\title{
Busca, acesso e disseminação da informação científica de cientistas, cientistas sociais e humanistas
}

\author{
Fernando César Lima Leite \\ Universidade de Brasília - UnB, Brasil
}

ANALYSIS

\begin{abstract}
Resumo
Apresenta resultados de estudo sobre características das atividades de busca, acesso e uso da informação, assim como hábitos de disseminação de pesquisadores de institutos de pesquisa. Do ponto de vista metodológico, é um estudo de abordagem mista que adotou a estratégia de triangulação concomitante. Os dados foram coletados por meio da aplicação de questionários, realização de entrevistas e lista de verificação e, em seguida, submetidos à análise estatística e de texto. O universo da pesquisa foi constituído dos pesquisadores vinculados às unidades de pesquisa do Ministério da Ciência, Tecnologia e Inovação e a base amostral foram os pesquisadores do Centro Brasileiro de Pesquisas Físicas (CBPF) e do Museu de Astronomia e Ciências Afins (MAST). Entre outros aspectos, os resultados revelaram que, resguardadas suas diferenças disciplinares, as atividades de busca, acesso e comunicação da informação científica, independentemente da área, ocorrem preponderantemente em ambiente digital; hábitos de comunicação são estimulados por motivações comuns a físicos e a cientistas sociais e humanistas; compartilhar o conhecimento e busca por visibilidade constituem os principais motivos para a disseminação de resultados de pesquisa; físicos estão naturalmente inseridos no contexto do acesso aberto à informação científica.
\end{abstract}

Palavras-chave

Comunicação científica ; Fluxo da informação científica ; Padrões de comunicação ; Produção do conhecimento científico ; Ciências ; Ciências sociais ; Humanidades ; Brasil

\section{Search, access and dissemination of scientific information from scientists, social scientists and humanists}

\begin{abstract}
This paper presents results of study on the characteristics of search activities, access to and use of information, and dissemination habits of researchers from scientific research institutes. From the methodological point of view, it is a mixed methods study which adopted the concurrent triangulation strategy. Data were collected through questionnaires, interviews and checklist, and then submitted to statistical and text analysis. The research sphere was consisted of researchers linked to the research units of the Ministry of Science, Technology and Innovation, and the sample basis were the researchers of the Brazilian Centre for Physics Research (CBPF) and Museum of Astronomy and Related Sciences (MAST). Among other aspects, the findings shows that the safeguarded their disciplinary differences, search, access and communication activities, regardless of the knowledge area, occurring mainly in the digital environment; communication habits are stimulated by motives common to scientists and social scientists and humanists, share knowledge and visibility are the main reasons for the dissemination of research results, physicists are naturally within the open access context.
\end{abstract}

\section{Keywords}

Scholarly communication ; Scholarly information flow ; Communication patterns ; Scholarly knowledge production ; Sciences ; Social sciences ; Humanities ; Brazil 


\section{Introdução}

A produção do conhecimento científico é uma atividade funcionalmente dependente do sistema de comunicação científica que o envolve. As funções da comunicação científica, discutidas por Kaplan \& Storer (1968), Menzel (1966) e Roosendaal \& Geurts (1998), entre outros aspectos, destacam o fluxo da informação que alimenta e que resulta das atividades de pesquisa, ou seja, referem-se à dinâmica de acesso e disseminação da informação. Nesse sentido, na medida em que determina os modos como pesquisadores acessam e disseminam informação, a comunicação científica torna-se um componente crucial para atividades de gestão da informação científica. Por esta razão, é imprescindível que sistemas destinados à gerenciar informação necessária e resultante das atividades de pesquisa considerem as diferenças disciplinares expressas nos modos como pesquisadores produzem conhecimento e acesso e disseminam a informação no contexto da ciência. Esta comunicação refere-se à resultados de pesquisa que teve como objetivo a proposição de modelo genérico de gestão da informação científica para instituições de pesquisa, tendo por base os fundamentos da comunicação científica e do acesso aberto. Mais especificamente, relata descobertas do estudo relacionadas com o mapeamento das características das atividades de busca, acesso e disseminação da informação científica desempenhadas por pesquisadores de diferentes áreas do conhecimento e a sua percepção a respeito.

\section{Metodologia}

Trata-se de uma pesquisa de abordagem mista, ou seja, foi operacionalizada com base na combinação de métodos qualitativos e quantitativos para a coleta e análise dos dados. Nesta perspectiva, adotou a estratégia de triangulação concomitante, onde dados quantitativos e qualitativos foram coletados simultaneamente e, em seguida, integração e comparados lado a lado.

A pesquisa teve como sujeito pesquisadores vinculados aos institutos de pesquisa do Ministério da Ciência, Tecnologia e Inovação (MCTI). Estabeleceu-se como parâmetro para a escolha de duas instituições a aplicação dos critérios produtividade científica e representação de diferentes divisões do conhecimento. Para o primeiro critério, adotou-se a quantidade de recursos de informação indexados na plataforma Web of Science. De acordo com a plataforma, entre os institutos de pesquisa vinculados ao MCTI, o Centro Brasileiro de Pesquisas Físicas (CBPF) encabeçou a lista, e, portanto, foi selecionado para o estudo dentro do critério produtividade. Da aplicação do primeiro critério para a definição da amostra, que resultou na escolha do CBPF, foi possível aplicar o segundo critério, que foi a representação de diferentes divisões do conhecimento. Por contemplar tanto disciplinas das ciências sociais quanto das humanidades, do ponto de vista das práticas de produção do conhecimento, o MAST foi considerado o instituto de pesquisa que mais se diferencia do CBPF. Desse modo, a amostra foi constituída de todos os pesquisadores doutores das ambas as instituições. A relação entre objetivos da pesquisa, fontes, instrumentos de coleta e análise dos dados estão descritos nos quadro 1.

\begin{tabular}{|c|c|c|c|}
\hline Objetivo & Fontes & Coleta de dados & Análise de dados \\
\hline \multirow{6}{*}{$\begin{array}{l}\text { Mapear atividades de busca, } \\
\text { acesso e uso da informação, } \\
\text { assim como hábitos de } \\
\text { comunicação científica de } \\
\text { pesquisadores de institutos de } \\
\text { pesquisa }\end{array}$} & \multirow{2}{*}{ Pesquisadores } & Questionário $^{1}$ & Análise estatística \\
\hline & & Entrevista $^{2}$ & Análise textual \\
\hline & Plataforma Lattes & Lista de verificação $^{3}$ & Análise estatística \\
\hline & \multirow[b]{2}{*}{ Pesquisadores } & Questionário & Análise estatística \\
\hline & & Entrevistas & Análise textual \\
\hline & Plataforma Lattes & Lista de verificação & Análise estatística \\
\hline
\end{tabular}

Quadro 1 : Objetivos da pesquisa

\section{Análise e discussão dos resultados}

No primeiro momento, os pesquisadores foram questionados sobre suas preferências pelos meios impressos ou digitais para terem acesso a recursos de informação necessários para realizar suas atividades. Mais da metade dos pesquisadores do CBPF (65\%) que responderam ao questionário preferem o acesso à informação a partir de meios digitais, restando ainda aproximadamente um terço que afirmou preferir as duas 
alternativas equilibradamente (figura 1). Por outro lado, todos os pesquisadores do MAST consideram os dois meios como relevantes para suas atividades de acesso à informação. Em comentário sobre a questão, um pesquisador do CBPF afirmou utilizar informação em meio impresso especialmente quando necessita de artigos científicos mais antigos e livros, correspondendo a uma proporção menor do que os que acessa por meio digital. Os benefícios dos meios digitais têm sido amplamente percebidos não somente nas ciências e tecnologia, mas também ciências sociais e humanidades, como sugere Borgman (2007) e como demonstrado por Haridasan e Khan (2009). Questionados a respeito da importância das tecnologias para o acesso à informação que necessitam para realizar suas pesquisas, por razões similares todos os pesquisadores consideram alta a relevância.

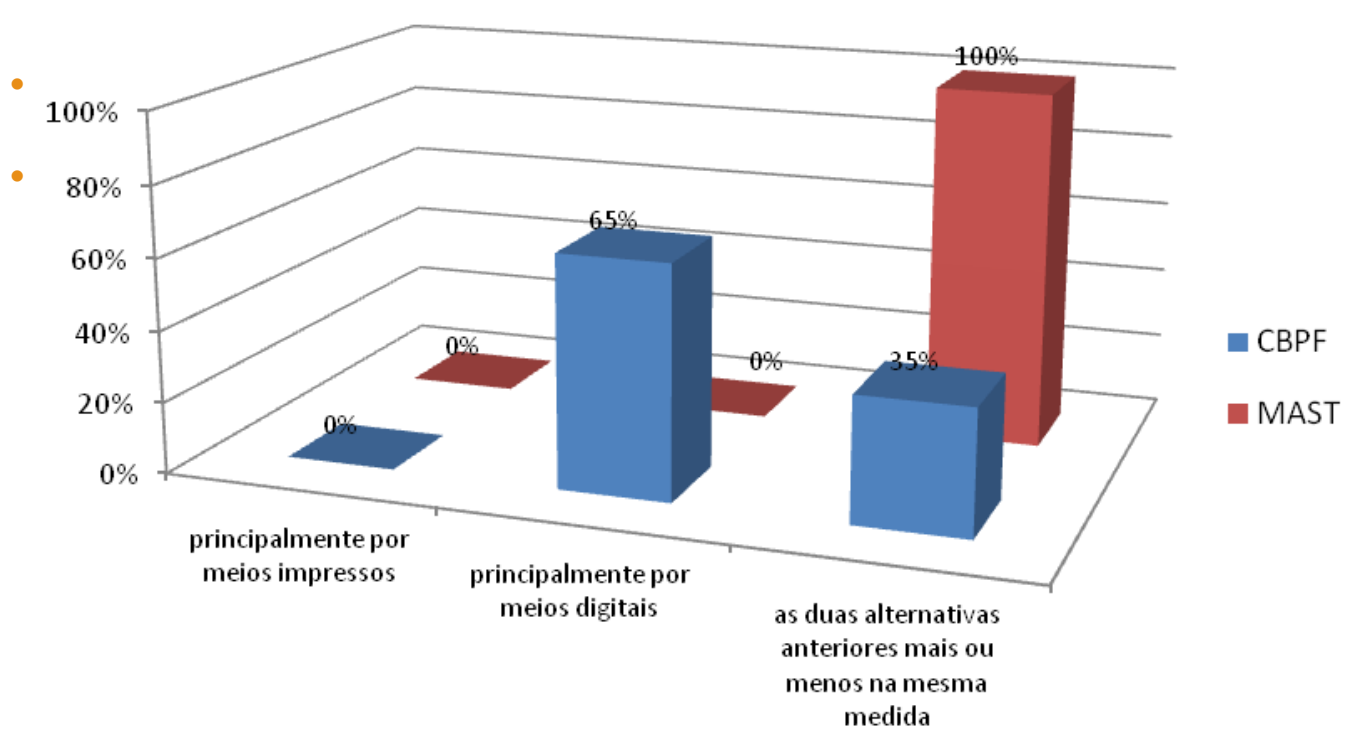

Figura 1: Preferência por meios impressos ou digitais para acessar a informação

Em seguida, os pesquisadores puderam assinalar, em uma lista, quais recursos ou serviços de informação constituem os principais insumos para suas atividades com pesquisa, ou seja, dentre os listados, quais ele precisa ter acesso e utiliza no desenvolvimento de suas pesquisas (figura 2).

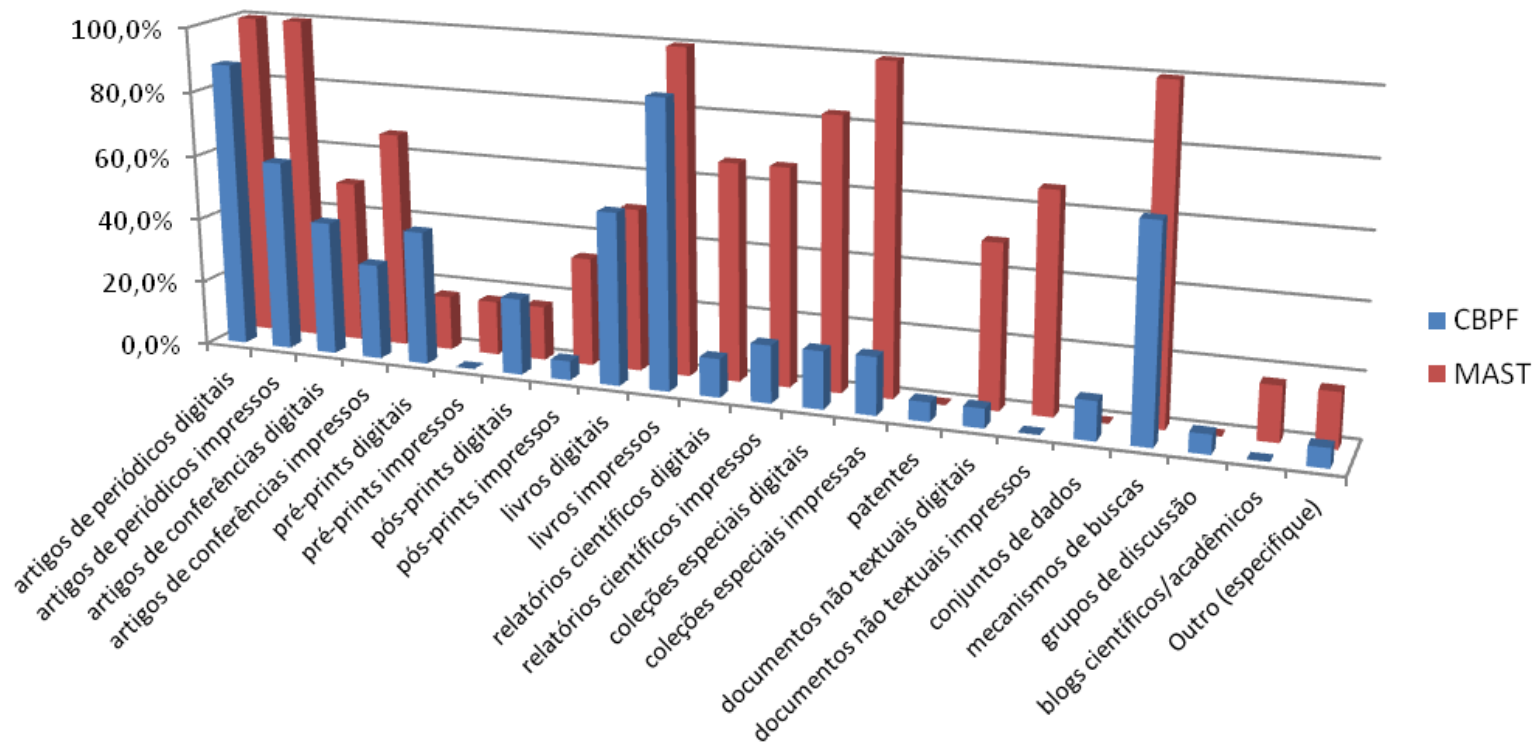

Figura 2: Recursos e serviços de informação de maior relevância 
Recursos de informação científica convencionais (artigos de periódicos, artigos de anais de conferências e livros), em suporte digital ou impresso, são fundamentais para ambas as áreas, constituindo-se no conjunto de recursos mais utilizados. Evidentemente, o grau de importância atribuído e o formato, impresso ou digital, é variável. Em importância, artigos de periódicos para físicos são mais relevantes que outros conteúdos e para cientistas sociais e humanistas têm o mesmo valor que outros tipos de recursos. Por outro lado, estes mesmos recursos de informação em formato impresso foram indicados como importantes, em menor quantidade por pesquisadores do CBPF e, com igual ocorrência, para pesquisadores do MAST. Tais resultados para o meio impresso correspondem a padrões de comunicação científica amplamente divulgados na literatura da área. Os resultados para o meio eletrônico encontram eco, igualmente, em um amplo número de estudos que apontam para o aumento gradual da substituição ou complementaridade do impresso pelo eletrônico.

Com exceção de livros, é possível que a importância do suporte impresso esteja relacionada ao uso propriamente dito, e não à busca e acesso, que ocorrem predominantemente em ambiente digital. Tal afirmativa encontra respaldo nas análises quantitativa e qualitativa sobre a importância dos meios digitais, discutidas anteriormente. Como visto, artigos de periódicos são o principal recursos de informação para físicos e estão e possuem igual importância para cientistas sociais e humanistas. Em certa medida, essa constatação reforça relato de Over et al (2005), que descobriram que o artigo de periódico científico é o recurso de informação mais utilizado por pesquisadores em todas as áreas do conhecimento. Diante dessa constatação, cabe mencionar a influência das tecnologias de informação e comunicação nessa mudança de comportamento, visto que, até um determinado momento, os periódicos científicos constituíam canal preferencial de determinadas áreas do conhecimento. A emergência e adoção de tecnologias parece ter influenciado sobremaneira os hábitos de comunicação científica formal, inclusive, e mais recentemente, de cientistas sociais e humanistas. Artigos de conferências tiveram uma importante consideração por pesquisadores das duas instituições. Essa importância certamente está relacionada ao fato de artigos de conferências, segundo Borgman (2007), constituírem fontes de informação cruciais sobre pesquisas em andamento e pesquisas recém concluídas.

Em pesquisa que empregou a análise de citações, Budd e Christensen (2003) descobriram que cientistas sociais utilizam uma variedade de recursos de informação ao longo de suas atividades de pesquisa e publicação. Cerca de $48 \%$ do total de citações foram feitas a artigos de periódicos, $42 \%$ a livros e o restante de citações foi distribuído em working papers, documentos governamentais, matérias jornalísticas e outros. Ou seja, os autores constataram que a maior parte corresponde a recursos de informação convencionais, tal como os resultados aqui obtidos e discutidos. Um outro estudo sobre o uso de recursos acadêmicos digitais por cientistas sociais e humanistas, baseado em análise citações, foi realizado por Yang et al (2009). Os autores concluíram que na China há um impacto observável de fontes de informação digitais online nas citações feitas em artigos de periódicos das ciências sociais e humanidades, muito embora haja diferenças significativas entre as disciplinas que compõem essas áreas. Uma das divergências dos resultados de Budd e Christensen em relação aos hábitos dos pesquisadores do MAST refere-se ao uso de artigos publicados em anais de conferências. No estudo dos autores, menos de $1 \%$ do total de citações foram feitas a artigos publicados em anais de conferências, enquanto cerca de metade dos pesquisadores investigados afirmaram fazer uso. O modelo de comunicação científica de Hills (1983) e Søndergaard et al (2003) a literatura cinzenta no fluxo da informação científica. A discrepância observada talvez possa ser explicada pela ideia de que:

o advento e o uso de novas tecnologias, uma tendência prevalecente na sociedade do século $\mathrm{XXI}$, tem criado uma consciência crescente da necessidade de incorporar a literatura cinzenta ao lado da branca, um limite que está se tornando menos distinto e que pode tornar-se translúcido em um futuro não tão distante (VASKA, 2010, p. 11).

Ainda no contexto das ciências sociais, pesquisa realizada pela British Academy (e-Resources for Research in the Humanities and Social Sciences, 2005) trouxe resultados semelhantes aos identificados na presente pesquisa. Os resultados indicaram a importância dos artigos de periódicos em todas as disciplinas das ciências sociais e humanidades, inclusive em formato digital. Ao mesmo tempo continua a relevância de livros e monografias impressas, e, em certas disciplinas, documentos de natureza arquivística, como revelado pela literatura (BARUCHSON-ARBIB \& BRONSTEIN, 2007; BROCKMAN ET AL, 2001; BUDD \& CHRISTENSEN, 2003; MARON \& SMITH, 2008; SPARKS, 2005). 
Como visto, não surpreendentemente, na física o artigo de periódico constitui o principal insumo informacional para o desenvolvimento das atividades de pesquisa, seguido dos artigos de anais de conferências e livros, como será discutido a seguir. Brown (1999) chegou a esta mesma conclusão. Seu estudo revelou que físicos, químicos e astrônomos indicaram que os periódicos são o principal insumo informacional de suas pesquisas. A mesma investigação apontou que $47 \%$ físicos participantes do estudo utilizam anais de conferências, como também indicaram os pesquisadores do CBPF. Além disso, cerca de $40 \%$ dos físicos que responderam ao questionário da tese indicaram utilizar pré-prints em formato digital (e-prints), o que, definitivamente, não corresponde a um padrão nas ciências sociais e humanidades, a despeito da pequena indicação. Na verdade, o uso desse tipo de recurso de informação por físicos, de acordo com os resultados, ocorre exclusivamente em suporte digital, como previsto em diversos modelos de comunicação científica de Hurd (1996, 2000, 2004). A ampla utilização de e-prints por físicos foi apontada e estudada por diversos autores, reforçando os resultados aqui relatados (BROWN, 1999, 2001; GENTIL-BECCOT et al, 2008; JAMALI \& NICHOLAS, 2008, 2010; HEMMINGER, 2007; LAWAL, 2002; PINFIELD, 2001). Dentre os principais arquivos digitais de e-prints está o arXiv, que de acordo com a percepção dos entrevistas, exerce um imprescindível papel em suas atividades de busca, acesso e uso da informação científica que necessitam.

Outro aspecto relevante foi a utilização de livros, onde a adoção do suporte digital é menor em ambas as áreas, predominando o suporte impresso. Relatórios científicos, por outro lado, em formato digital e impresso, foram indicados como relevantes por maior parte dos cientistas sociais e humanistas e pouco para físicos. Como foi possível constatar, coleções especiais, documentos não textuais, em suporte impresso ou digital, são relevantes para pesquisadores das ciências sociais e humanidades. Como outras opções de respostas, um pesquisador do CBPF afirmou ser relevante o contato permanente com pesquisadores estrangeiros por meio de visitas de ambos os lados, e o pesquisador do MAST afirmou utilizar coleções de objetos. Os resultados corroboram a perspectiva de Borgman (2007), segundo a qual a despeito das muitas atividades comuns, tanto os artefatos de informação quanto as práticas variam em razão das disciplinas. Os artefatos variam de acordo com as escolhas a respeito das fontes de dados, juntamente com o que, quando, onde e em qual forma disseminar os produtos de seu trabalho. Práticas científicas variam em função das maneiras que pesquisadores criam, usam e compartilham documentos, dados e outras formas de informação (BORGMAN, 2007, p. 179).

Os principais recursos, serviços, assim como as estratégias empreendidas para ter acesso à informação necessária ao desenvolvimento de suas atividades como pesquisadores também foram tema abordado nas entrevistas. Muitos dos aspectos discutidos a partir dos resultados obtidos da aplicação dos questionários também surgiram nas percepções expressas pelos entrevistados. As citações a seguir sumarizam os pontos mais relevantes das respostas obtidas quando questionados a respeito dos principais recursos, serviços e estratégias de busca e acesso à informação que necessitam.

\begin{tabular}{|c|}
\hline \multicolumn{1}{|c|}{ Quais as principais estratégias que você utiliza para buscar e acessar informação que precisa para fazer pesquisa? } \\
Você precisa acessar o que? Onde?
\end{tabular}

Quadro 2 : Citações obtidas dos questionados - recursos, serviços e estratégias (continua) 


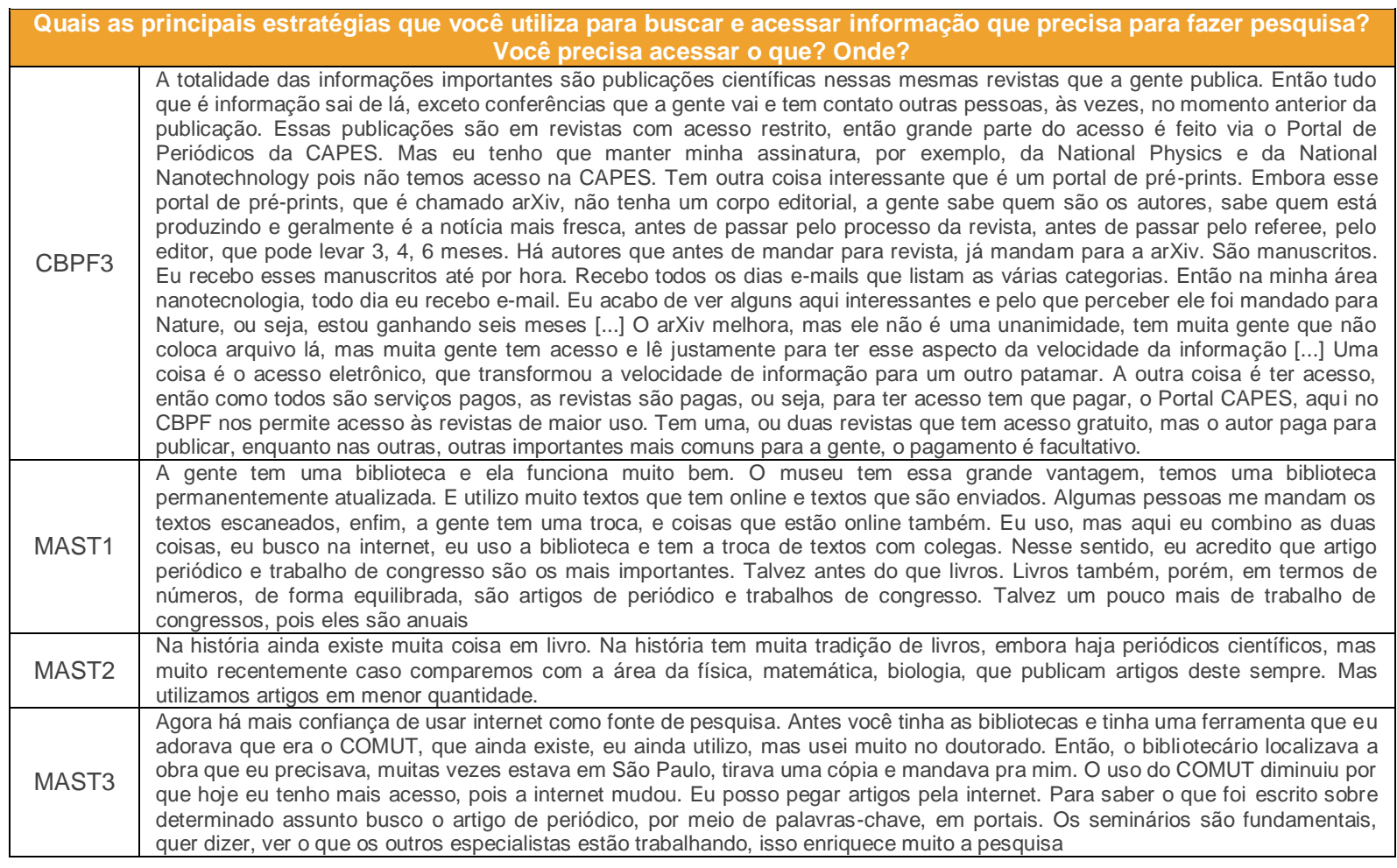

Quadro 2 : Citações obtidas dos questionados - recursos, serviços e estratégias (conclusão)

Além dos aspectos apontados no levantamento quantitativo e aprofundados nas entrevistas, outros seis pontos relevantes, que incidem diretamente sobre a busca, acesso e uso da informação científica, foram mencionados pelos entrevistados. Entre esses pontos relevantes destacam-se, em primeiro lugar, os problemas decorrentes das restrições de acesso aos conteúdos dos periódicos científicos mediante assinatura (ODLYZKO, 2006; WILLINSKY, 2006). Em segundo, a predominância do meio digital para a busca e acesso à informação (MARON \& SMITH, 2008). Em terceiro lugar foi mencionada a relevância da circulação de e-prints, especialmente por meio do arXiv. Em quarto lugar estão os modelos de negócios de periódicos científicos (COCKERILL, 2006; GUMIEIRO, 2009; SUBER, 2010; SCHROTER \& TITE, 2006; WILLINSKY, 2006). Em quinto, a utilização de meios digitais não convencionais para o acesso à informação científica (MARON \& SMITH, 2008). Finalmente, a importância das conferências (BORGMAN, 2007).

Os pesquisadores responderam a questão sobre quais fatores influenciam a escolha das fontes e recursos de informação que servem de insumo para a realização das suas pesquisas (figura 3). Em ordem de importância, os três primeiros fatores que reuniram maior quantidade de respostas, na perspectiva dos pesquisadores de ambas as instituições, foram, respectivamente, a credibilidade, ter sido submetido à avaliação por pares e a disponibilidade de texto completo. Para os pesquisadores do MAST, este último fator é ainda mais determinante do que ser avaliado por pares. Do MAST também foi apontada a originalidade como outro fator, não previsto como opção de resposta. Os mesmos fatores foram apontados como importantes por pesquisadores da física e das ciências sociais e humanidades. A credibilidade e avaliação por pares constituem fatores relacionados entre si e intimamente ligados à questão da qualidade, aspecto que influencia o uso da informação, especialmente no contexto da ciência. É interessante notar que a disponibilidade de texto completo esteve entre presente na opinião de pesquisadores das duas áreas. Essa constatação encontra reforço em resultados discutidos anteriormente, quando pesquisadores consideraram que as tecnologias de informação encerram um importante papel na busca e acesso à informação. 


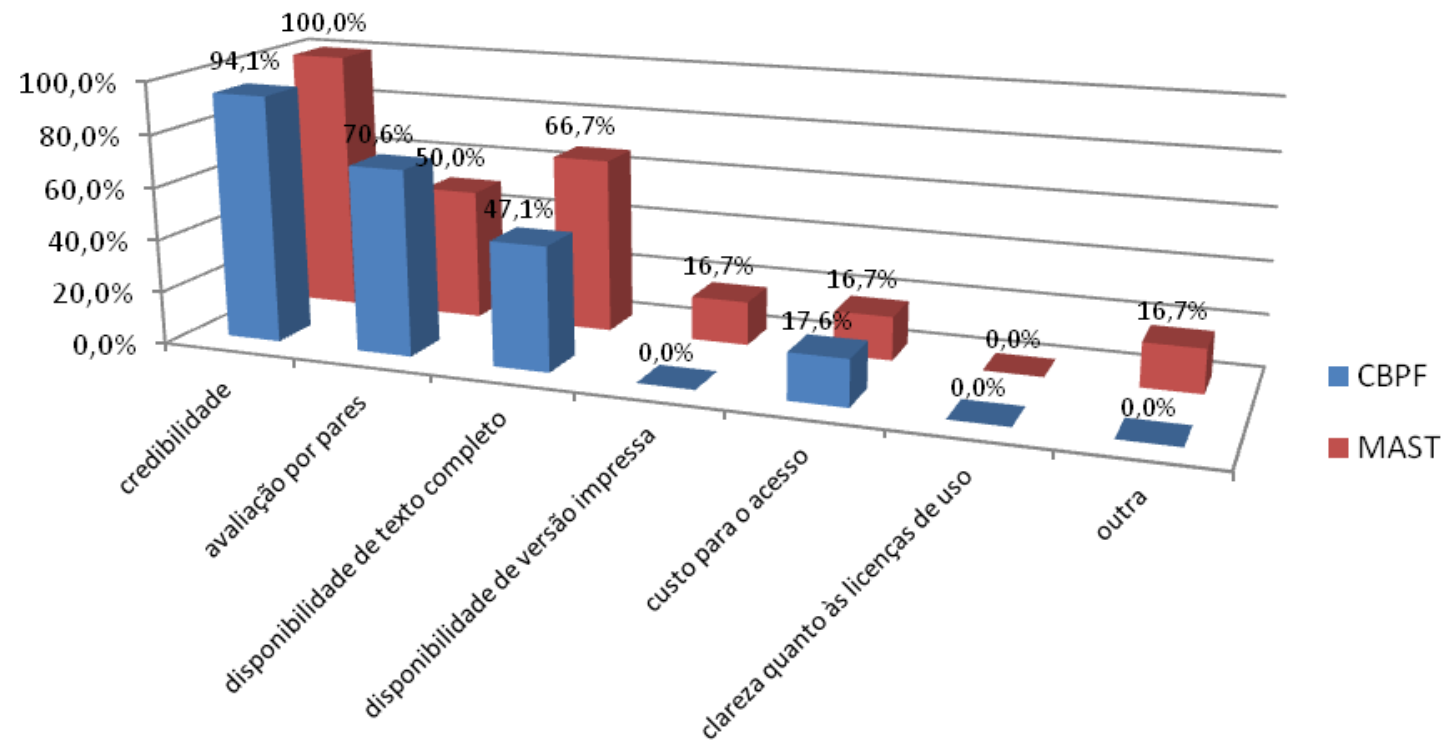

Figura 3: Fatores que influenciam a escolha das fontes e recursos de informação

Houghton et al (2003) também exploraram essa questão, chegando a resultados similares. Para pesquisadores das ciências e medicina, os três fatores que mais foram considerados como muito importantes na escolha de fontes de informação estão a avaliação por pares, seguido da credibilidade e atualidade. Por outro lado, pesquisadores das ciências sociais, humanidades e artes consideraram como muito importantes a credibilidade, avaliação por pares e atualidade. A disponibilidade de texto completo assim como a possibilidade de acessar diretamente em seu computador foram considerados como importantes por ambas as áreas.

A pesquisa tratou de aspectos relacionados com os hábitos de disseminação da informação de pesquisadores das duas instituições e também do modo como o percebem. Antes do reconhecimento das principais estratégias empreendidas e veículos escolhidos para a disseminação dos resultados de pesquisa, optou-se por explorar as razões primeiras que levam pesquisadores a realizá-la. Compreender as motivações que levam pesquisadores a disseminar os resultados de suas pesquisas pode parecer, em um primeiro momento, a busca por respostas óbvias. Entretanto, é fundamental que tais motivações sejam explicitadas de modo a compreender as forças que influenciam o fluxo da informação.

Quando questionados a respeito das motivações primeiras para disseminar resultados de suas pesquisas, tanto as motivações de físicos como as de cientistas sociais e humanistas giram em torno das mesmas razões (figura 4).

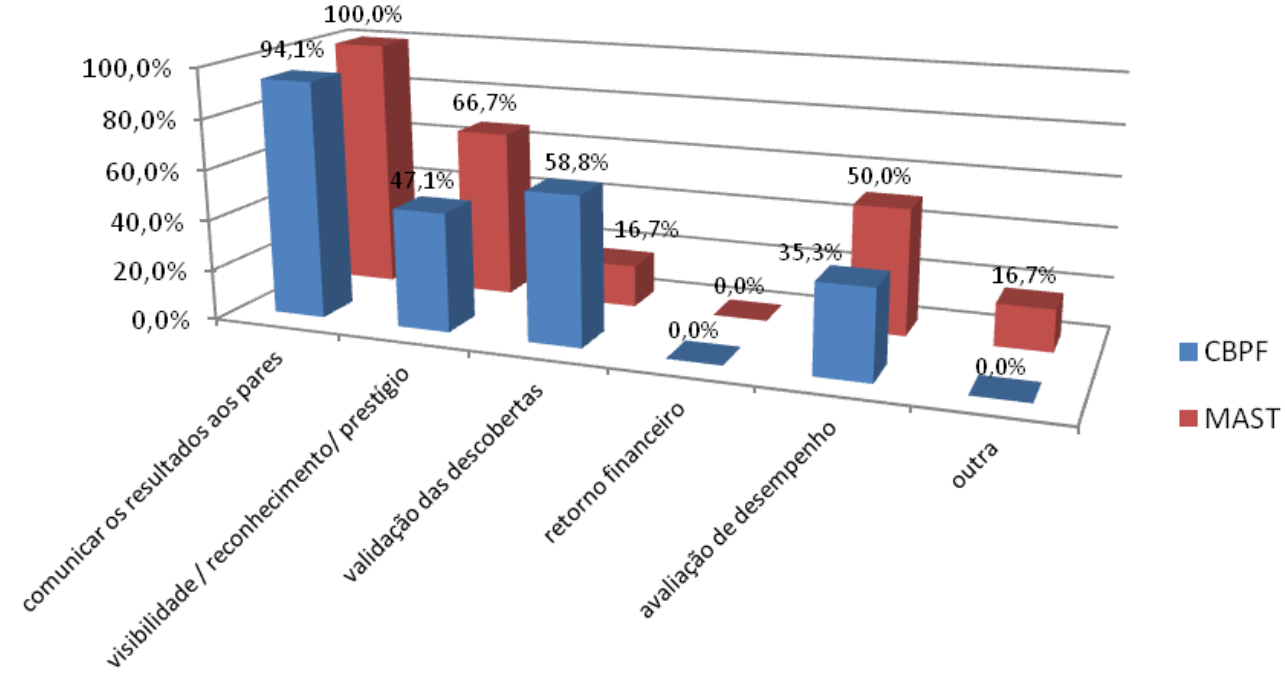

Figura 4: Principais motivações para a disseminação de resultados de pesquisa 
De acordo com resultados dos questionários, em primeiro lugar está necessidade de comunicar suas descobertas de modo que a ciência possa avançar. Em seguida, está a busca por visibilidade e reconhecimento, precedendo fatores relacionados com a avaliação de desempenho nas instituições em que mantém vínculo. Mais do que visibilidade - importante motivação para ambas as áreas-, físicos buscam a validação de suas descobertas.

As motivações para disseminar resultados de pesquisa foram tratadas também nas entrevistas. Nesse momento, os pesquisadores puderam refletir a respeito do tema e, com isso, foi possível compreender de modo mais aprofundado suas razões. Sobre essa questão, Borgman (2007) alerta para o fato de que pesquisadores querem tornar suas publicações amplamente disponíveis para legitimar, disseminar e tornar seu trabalho acessível para outros pesquisadores. Essa perspectiva sublinhada pela autora esteve largamente presente nos discursos dos entrevistados. De um modo geral, todos eles apontaram invariavelmente as mesmas motivações, que estão relacionadas com a necessidade de tornar público o conhecimento gerado de modo que outros possam utilizá-los e gerar novos conhecimentos. Houve, portanto, convergência nas respostas, como ilustram as citações a seguir.

\begin{tabular}{c}
\multicolumn{2}{|c|}{ Quais as suas principais motivações para comunicar os resultados de suas pesquisas? Você faz isso com quais } \\
intenções?
\end{tabular}

\section{Quadro 3 : Citações obtidas dos questionados - motivações}

As razões por trás das atividades de disseminação de resultados de pesquisa também estiveram presentes no estudo realizado Houghton et al (2003). Entre as motivações mais importantes para os participantes da pesquisa estão a comunicação do trabalho que realiza aos pares e a mensuração de desempenho de pesquisa, apontados por mais de $60 \%$ dos pesquisadores. $O$ reconhecimento esteve como a motivação seguinte, tal como revelado por físicos, cientistas sociais e humanistas participantes do estudo aqui relatado. A literatura registra, de fato, que a razão prioritária para publicar é a necessidade de comunicar os resultados aos pares - de modo que esses possam acessá-los e a ciência possa avançar-, seguida de necessidades de avanços na carreira e obtenção de prestígio e visibilidade (SWAN, 2004, 2006; SWAN \& BROWN, 2004, 2005). Não é surpreendente que, tal como os resultados ora discutidos, o retorno financeiro não constitua uma motivação. Ora, considerando as razões primeiras, que se distanciam completamente de qualquer expectativa financeira, modelos de publicação científica que de algum modo taxam o acesso aos seus conteúdos vão de encontro às expectativas dos autores. Por fim, outra motivação foi apontada por pesquisador do MAST. Em sua observação, a comunicação dos resultados de suas pesquisas é um compromisso social, o que justifica, inclusive, a percepção de seus proventos.

Após a compreensão das razões que levam pesquisadores a disseminar os resultados de pesquisa, passa-se ao relato e discussão das principais estratégias empreendidas e dos veículos selecionados para a comunicação científica (figura 5). Para pesquisadores das duas instituições, o fator de maior influência nesta decisão diz respeito à reputação do periódico ou da editora que o publica. Em seguida, a possibilidade de disseminação do trabalho em nível internacional também corresponde a um fator determinante nas duas áreas. O fator de impacto do periódico constitui um aspecto importante para pesquisadores da física, mas não está entre as principais preocupações de pesquisadores do MAST. Estes, também apontaram como fator relevante a 
possibilidade tornar uma cópia digital do trabalho disponível na internet. Outras respostas, de pesquisadores do CBPF, incluem a compatibilidade entre o foco da revista e o tópico da pesquisa realizada e também os custos de publicação. Pesquisa realizada por Rowlands e Nicholas (2005) junto a milhares de pesquisadores em todas as áreas do conhecimento também abordou a questão da escolha do veículo para publicação de resultados de pesquisa. Entre aqueles fatores que mais são levados em consideração no momento da escolha de onde publicar os resultados de suas pesquisas está, em primeiro lugar, a reputação do periódico, seguido do seu público leitor, fator de impacto, velocidade de publicação e reputação do corpo editorial. Existência de versão digital do artigo e possibilidade de distribuição de pré ou pós-prints estiveram entre os fatores não tão relevantes. Houghton et al (2003) também exploraram esses fatores e descobriram que a existência de peer review, assim como o prestígio do veículo são os fatores mais relevantes. Resultados de Over et al (2005) também apontaram o prestígio do periódico como muito importante, seguido de sua distribuição internacional e especialidade/foco. Dentre os fatores ranqueados como muito importantes, em estudo similar realizado por Moore (2011), estão audiência, qualidade do processo de avaliação pelos pares e o prestígio do periódico.

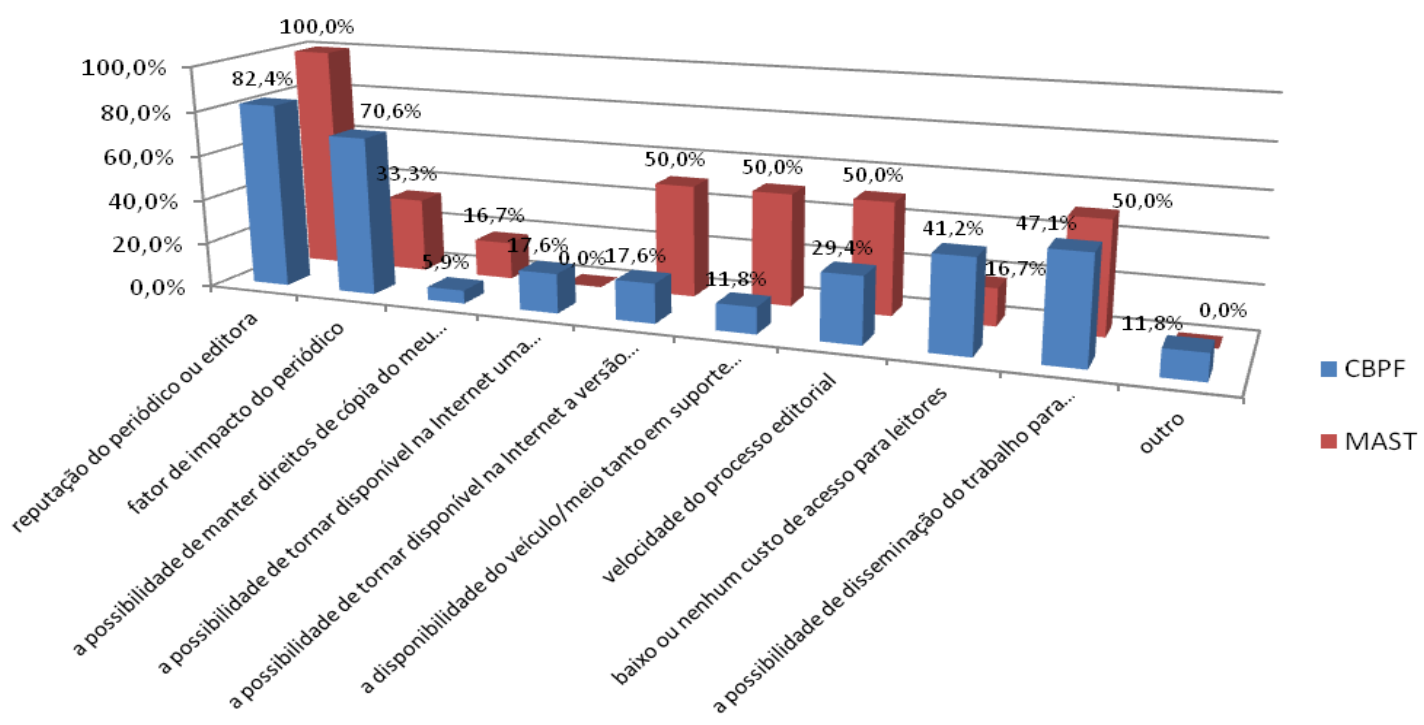

Figura 5: Fatores condicionantes da escolha do veículo de publicação

No período em que Houghton et al (2003) e Rowlands e Nicholas (2005) realizaram seus estudos, os pesquisadores consideraram a disponibilidade de uma versão digital online como pouco importante. Contrariamente, esses fatores foram considerados relevantes pelos pesquisadores aqui estudados, sobretudo por cientistas sociais e humanistas, tal como nos resultados recentes de Moore (2011). É possível, portanto, inferir que a percepção da necessidade de versões digitais que facilitam o acesso tenha variado em razão do tempo e, sem dúvida, das iniciativas implementadas nos últimos anos, mais especialmente no contexto do acesso aberto.

Físicos, surpreendentemente, não apontaram a possibilidade da versão digital como um fator determinante. Isso talvez possa ser explicado pelo fato de que para essa comunidade o formato digital seja uma realidade bem estabelecida. Isso porque a distribuição de e-prints constitui uma prática comum na área, e que ocorre, como visto anteriormente, preponderantemente em meio digital, o que não implica na necessidade premente de ressaltar o meio digital, intrínseco em suas práticas. Essa questão é de tamanha importância ao ponto que Hurd (1996, 2000, 2004), no contexto das ciências, vem recorrentemente discutindo modelos de processos de comunicação científica ao longo dos anos fundamentalmente baseados no meio digital. Curiosamente, nem os resultados aqui discutidos, nem tão pouco os resultados de estudos realizados anteriormente destacaram a importância da retenção de direitos de cópia dos trabalhos por parte dos autores. Muito embora incidam diretamente sobre a maior ou menor exposição dos resultados de pesquisa junto à comunidade científica, a principal motivação para a atividade de publicação, como visto anteriormente, os modelos de licenciamento praticados por editores científicos não são levados em conta quando da escolha do veículo de publicação. Por outro lado, boa parte dos físicos compreende que a inexistência de barreiras financeiras para o acesso à informação científica publicada é um incentivo à sua ampla disseminação. Por fim, 
tanto físicos quanto cientistas sociais revelaram a preocupação com a disseminação internacional dos resultados de suas pesquisas, processo que tem sido facilitado à medida que as tecnologias de informação e comunicação avançam aliado aos desdobramentos do acesso aberto.

Perguntados sobre o meio principal a partir do qual disseminam resultados de pesquisas, a maior parte dos pesquisadores do MAST considera que utiliza tanto os meios impressos quanto os digitais, equilibradamente (figura 6). Essa constatação condiz com estudo realizado por Costa (1999) no contexto de cientistas sociais. A autora percebeu a complementaridade dos meios (impresso e digital) e propôs um modelo híbrido de comunicação científica que parece se aproximar das práticas aqui relatadas. Por outro lado, pesquisadores do CBPF dividiram-se equilibradamente entre aqueles que adotam predominantemente os meios digitais e aqueles que adotam os dois meios mais ou menos na mesma medida.

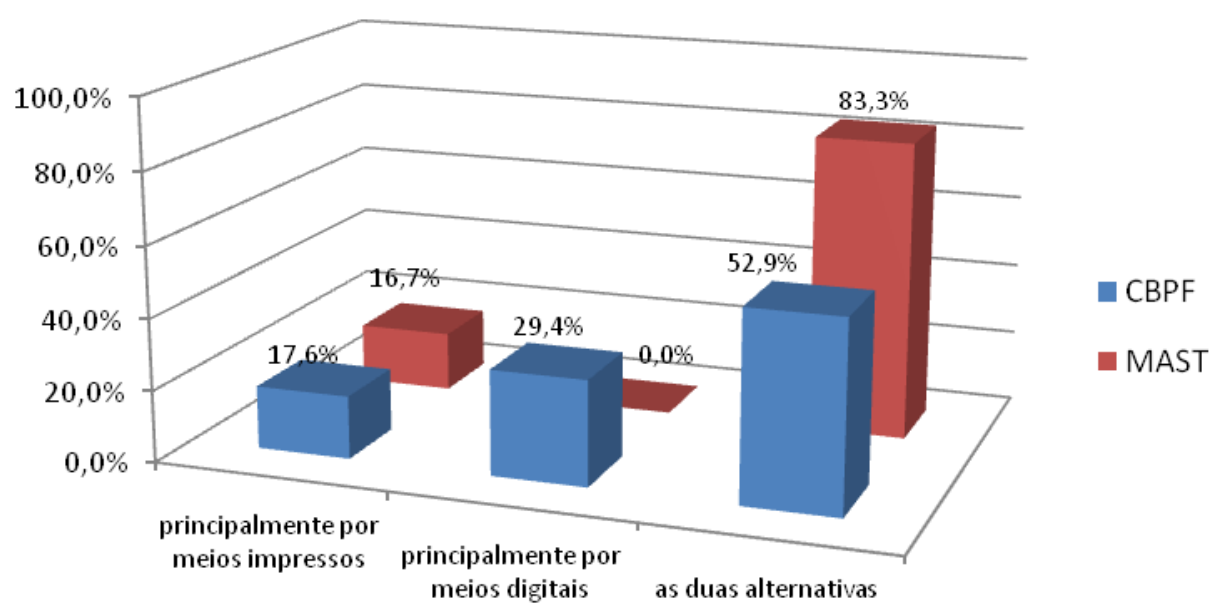

Figura 6: Meio principal de disseminação de resultados de pesquisa

Embora o equilíbrio entre meios digitais e impresso não sugira a predominância de um sobre o outro, os resultados a esse questionamento foram surpreendentes face à não consideração dos meios digitais como principais para a disseminação de resultados de pesquisa. Como será visto mais adiante, a percepção dos pesquisadores, captada com a realização das entrevistas, imputam maior peso aos meios digitais quando está em discussão a disseminação de seus trabalhos. É importante frisar, entretanto, que, veículos de comunicação científica baseados preponderantemente em meio impresso não atendem às expectativas de físicos, nem tão pouco de cientistas sociais e humanistas estudados.

A análise dos currículos Lattes dos pesquisadores permitiu conhecer características de seus hábitos de publicação (figura 7).

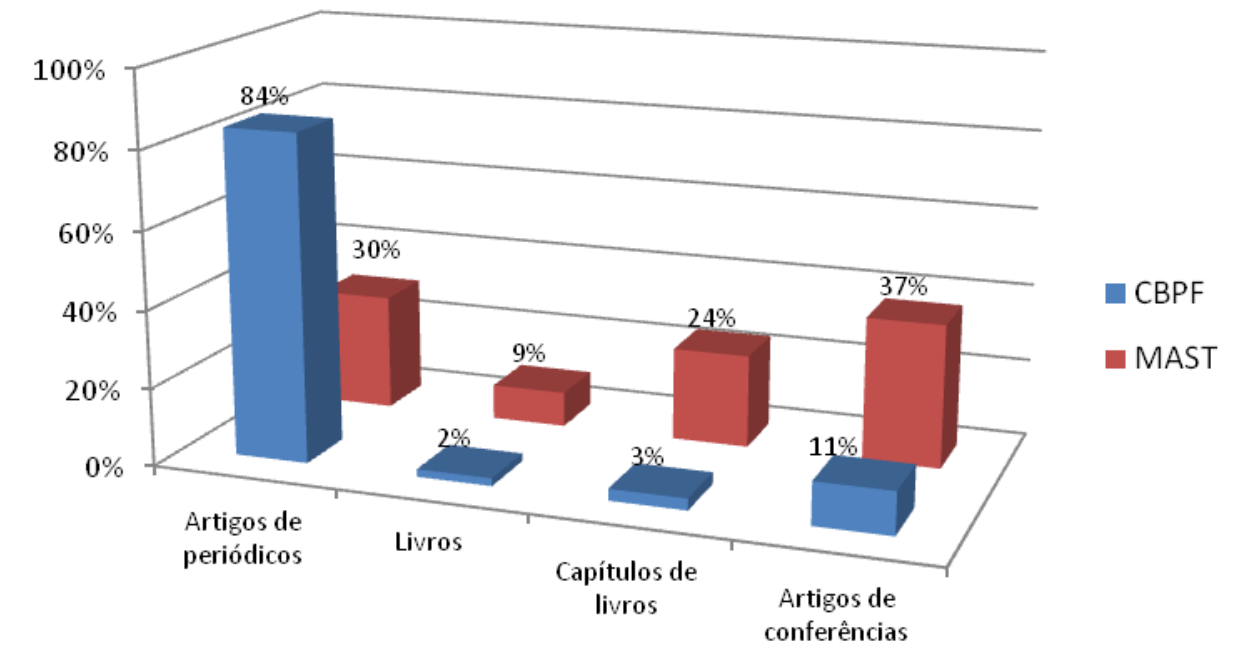

Figura 7: Comunicação científica formal de físicos e cientistas sociais e humanistas 
Foi possível tanto mapear a proporção de uso de diferentes canais de comunicação científica formal por pesquisadores de ambas as instituições, quanto compará-los. Cerca de $85 \%$ de toda a produção científica de pesquisadores do CBPF são artigos publicados em periódicos científicos. Esse hábito, correspondente de publicação de cientistas como um todo, reforçam os diferentes modelos (COSTA, 1999; HURD, 1996, 2000, 2004) derivados do modelo de processo de comunicação científica de Garvey e Griffith (1979).

Com uso significativamente menor (11\%), a participação e publicação de artigos em anais de conferências foi identificada como veículo para publicação de pesquisa, seguida de capítulos de livros e livros, com $3 \%$ e $2 \%$ respectivamente. Diferentemente dos pesquisadores vinculados ao CBPF, a análise dos dados coletados dos currículos Lattes dos pesquisadores vinculados ao MAST não apontou um veículo preferencial, e sim uma adoção equilibrada de diferentes veículos. Nesse caso, a maior parte da produção científica equivale a participação e publicação de artigos em anais de conferências, com 37\% do total. Artigos publicados em periódicos científicos correspondem a $30 \%$ do total da produção científica, seguidos da publicação de capítulos de livros, com $24 \%$ e de livros, com $3 \%$. Tendo em vista a proximidade dos números, exceto de livros, acreditase não ser possível afirmar, de fato, a existência de um canal preferencial, mas sim uma distribuição equilibrada por tipos de publicação.

Comparando os dados sobre hábitos de publicação com atividades de busca, acesso e uso da informação científica, discutidos da seção anterior, é possível apontar aspectos interessantes. Na física, há um equilíbrio entre produtores e consumidores de artigos de periódicos, ou seja, todos os pesquisadores utilizam e publicam artigos de periódicos. Quanto aos demais veículos, observa-se tendência maior de consumidores do que produtores. Ou seja, do ponto de vista formal, $84 \%$ dos físicos adotam a publicação de artigos de periódicos como a principal estratégia de comunicação formal. Embora o percentual de utilização de artigos como insumo para suas pesquisas seja igualmente alto, como visto na seção anterior, o uso de outros recursos de informação é mais recorrente do que a prática de publicação em outros veículos. Por outro lado, cientistas sociais e humanistas têm hábitos diferentes dos hábitos de físicos, considerando que seus hábitos de publicação formal estão equilibradamente distribuídos. A produção científica desses pesquisadores revelou, inclusive, maior publicação em anais de conferências do que até mesmo em periódicos.

Hábitos de comunicação científica não podem ser devidamente detectados unicamente a partir dos registros das atividades de publicação, como aqueles disponíveis nos currículos Lattes e discutidos há pouco. Em razão disso, pesquisadores de ambas as instituições foram solicitados a responder, por meio do questionário, quais seriam os principais canais de comunicação utilizados para disseminar os resultados de suas pesquisas (figura 8).

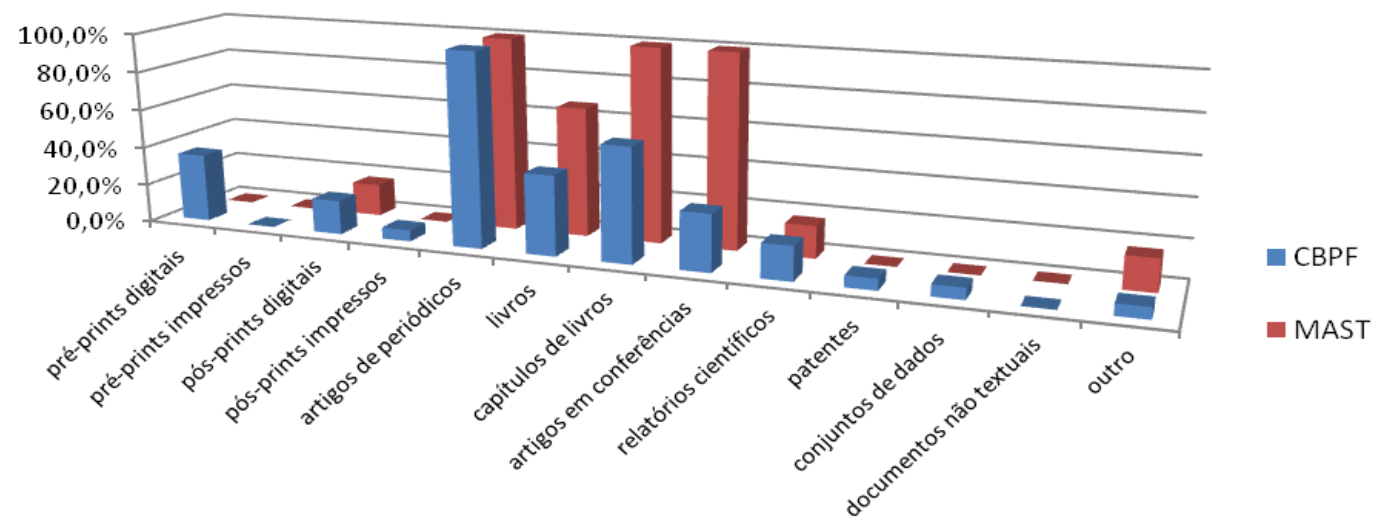

Figura 8: Comunicação científica formal de físicos e cientistas sociais e humanistas

Tal como identificado nos estudos de Moore (2011), os resultados da presente pesquisa revelam que formas tradicionais de publicações avaliadas por pares, incluindo monografias, livros e capítulos de livros, são as preferidas tanto por físicos quanto por cientistas sociais e humanistas. Percebe-se que maior parte das respostas está concentrada ao redor daquelas manifestações tradicionais da produção científica, ou seja, artigos de periódicos, livros, capítulos de livros e artigos publicados em anais de conferências, os quais pressupõem a participação em conferências. Os modelos de comunicação científica explorados na fundamentação teórica desta pesquisa enfatizam a comunicação científica formal, que tem como veículo de comunicação as diferentes 
manifestações da literatura científica (COSTA, 1999; GARVEY \& GRIFFITH, 1979; HILLS, 1983; HOUGHTON et al, 2009; HURD, 1996, 2000, 2004; LANCASTER \& SMITH, 1978; MIKHAILOV et al, 1984; UNISIST, 1971; SØNDERGAARD et al, 2003). Swan (2008) explica que esses veículos são vistos como tradicionais quando tem-se em mente o crescimento de novas formas de 'outputs' tais como blogs e wikis, que superaram sua reputação inicial como veículos triviais, aumentando, mais recentemente, seus usos como locus de disseminação de conteúdos científicos de alta qualidade. A esse respeito, Huang e Chang (2008) lembram, como têm feito autores por décadas, que a publicação é uma atividade essencial para pesquisadores em todas as disciplinas. Segundo os autores, as publicações são frequentemente consideradas como resultado formal das atividades de pesquisa e, embora a Internet tenha meios convenientes de lançamento e disseminação instantâneos das descobertas científicas, "os resultados de pesquisa em forma de publicações avaliadas por pares são ainda considerados como mais detentores de autoridade e reconhecimento" (HUANG \& CHANG, 2008, p. 1820).

A constatação da concentração das respostas em veículos convencionais vem ao encontro de resultados obtidos por Houghton et al (2003) e por Sparks (2005) que investigaram padrões de comunicação científica de diversas áreas. Os autores descobriram que, a despeito de formas mais peculiares de determinadas disciplinas, maior concentração estava em torno das diferentes manifestações do artigo de periódico (pré-prints, pós-prints e versões publicadas), anais de conferências e capítulos de livros. As repostas de pesquisadores vinculados ao MAST reforçam os resultados da análise de dados provenientes de seus currículos Lattes, ou seja, a distribuição equilibrada em diferentes canais de comunicação científica. A novidade nesse caso foi a ocorrência de resposta para relatórios científicos e pós-prints digitais, que dizem respeito a versões avaliadas, porém ainda não publicadas, de artigos de periódicos.

Como era de se esperar, 100\% dos pesquisadores vinculados ao CBPF apontou o artigo de periódico como canal de comunicação. Em relação aos resultados obtidos a partir de seus currículos Lattes, a novidade está explicitação da prática de distribuição de pré-prints e pós-prints, que dizem respeito, como será visto nos dados do levantamento qualitativo a seguir, a versões de artigos ainda não publicados em periódicos, predominantemente em suporte digital. Além disso, veio à tona também a utilização de capítulos de livros, e, em menor quantidade, livros, artigos publicados em anais de conferências e relatórios científicos.

Embora concentrados em torno de determinadas formas de comunicação, estão claras as diferenças nos padrões de comunicação entre as grandes áreas, como também percebido na literatura (GORRAIZ et al, 2009; HOUGHTON et al, 2003; HUANG \& CHANG, 2008) dentre centenas de trabalhos identificados na literatura). Com isso, e aliado aos dados dos currículos Lattes e das entrevistas, discutidos a seguir, vale relativizar comentário de Swan (2008), quando afirma que nas humanidades o artigo de periódico não é tão dominante quanto nas ciências naturais, enquanto as monografias permanecem como a rota principal para a disseminação dos trabalhos científicos. Não resta dúvidas que as monografias encerram um importante papel na disseminação de resultados de pesquisa de cientistas sociais, e, principalmente, humanistas, como afirma a autora. Entretanto, os pesquisadores estudados ofereceram importantes indícios de que esse papel está sendo compartilhado com outros veículos, ainda que convencionais.

Além da análise dos currículos Lattes e das respostas do questionário, os pesquisadores foram estimulados a falar a respeito de suas práticas de disseminação dos resultados de suas pesquisas. Físicos, em geral, relataram que a publicação de artigos de periódicos constitui e principal estratégia. Entretanto, foi recorrente a ideia de que o depósito de versões ainda não publicadas dos artigos em ambientes de aceso aberto agiliza e torna mais eficiente a disseminação dos resultados de pesquisa. O ambiente mais utilizado foi o ArXiv. Pesquisadores do MAST, por sua vez, mencionaram principalmente a publicação de trabalhos em anais de conferência e em periódicos científicos. Pesquisadores de ambas as áreas destacaram a importância das tecnologias para disseminar mais amplamente os resultados de suas pesquisas.

Houve convergências entre os resultados obtidos por meio das três estratégias de coleta de dados. Do mesmo modo que nas atividades de busca, acesso e uso da informação científica, os hábitos de comunicação científica, de acordo com dados coletados qualitativamente, giram em torno, sobretudo, da publicação de artigos de periódicos e outros veículos convencionais. Dentre esses veículos convencionais, que foram sinalizados principalmente por cientistas sociais e humanistas, mas também por físicos, estão a publicação de artigos em anais de conferências - além da participação nelas-, livros e capítulos de livros. A respeito de artigos publicados em anais de conferências, Borgman (2007, p. 53) afirma que quando as conferências científicas não publicam formalmente seus anais, espera-se que os artigos sejam publicados posteriormente em periódicos ou livros. Segundo a autora, tais artigos de conferências são vistos como meios de disseminação intermediários e semi- 
públicos. Borgman considera que conferências desse tipo devem oferecer ainda outras formas intermediárias de publicação, como manter páginas na internet em que os apresentadores podem postar seus artigos antes, durante ou depois do evento. Seja como manuscritos informais ou publicações formais, "artigos de conferências são frequentemente postados nas páginas pessoais dos autores ou em repositórios institucionais. Eles são fontes de informação cruciais sobre pesquisas em andamento e pesquisas recém concluídas". (BORGMAN, 2007, p. 53).

Fry (2006) constatou que no contexto da física de altas energias, os arquivos de e-prints constituem um dos principais veículos de comunicação científica. Físicos reforçaram nas entrevistas que os arquivos de eprints, em especial o arXiv, são úteis não apenas para a busca e acesso à informação, mas também para a comunicação dos resultados de suas pesquisas. É importante notar, no entanto, que Antelman (2006) ressalta a incidência de mais leitores de conteúdos em acesso aberto do que autores praticando o autoarquivamento.

Considerando especificamente a publicação de artigos de periódicos científicos como esforço para a caracterização da manifestação informacional dos resultados de pesquisa, foi possível identificar os idiomas mais freqüentes em que publicam (figura 9).

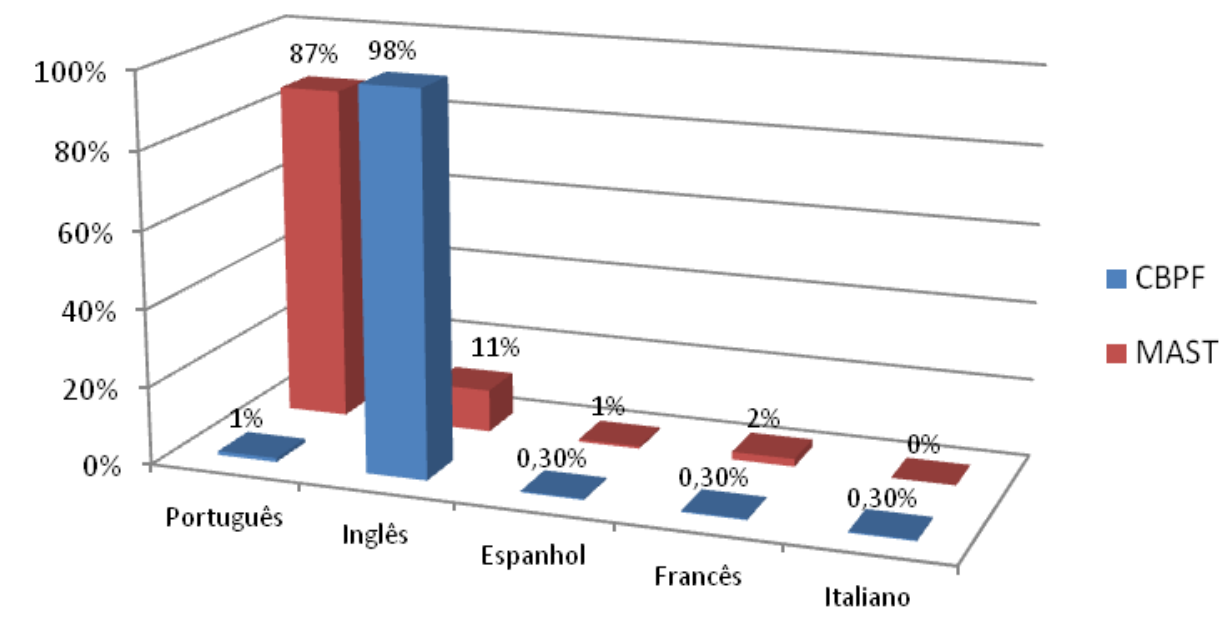

Figura 9: Idiomas predominantes na publicação de artigos de periódicos científicos

Quase a totalidade de artigos de periódicos de autoria de pesquisadores do CBPF são publicados em inglês (98\%). Diferentemente, pesquisadores vinculados ao MAST publicaram $87 \%$ dos seus artigos de periódicos em português, $11 \%$ em inglês e 3\% em francês ou espanhol. Over et al (2005) investigaram essa mesma questão no contexto de pesquisadores de todas as áreas do conhecimento, na Alemanha. Segundo seus resultados, cerca de $60 \%$ de cientistas sociais e humanistas adotam o alemão como idioma em suas publicações e $36 \%$ o inglês. Por outro lado, cerca de $90 \%$ dos pesquisadores das ciências naturais, que envolvem a física, adotam o inglês, e 10\% o alemão. A despeito das diferentes realidades das áreas, especialmente aquelas relacionadas com a natureza dos problemas de pesquisa, a possibilidade ou não de generalizações de descobertas e o grau de internacionalização, a língua inglesa tem sido considerada, ao longo do tempo, o idioma dominante para a comunicação de resultados de pesquisa.

Outro aspecto revelado de hábitos de comunicação científica, especialmente útil para iniciativas de gestão da informação científica, diz respeito aos responsáveis pelos processos editoriais. Nessa perspectiva, os pesquisadores foram questionados quanto à origem dos editores de suas publicações científicas. Como era de se esperar, em razão das ocorrências sobre idioma, de acordo com respostas dos pesquisadores do CBPF, toda a sua produção científica é publicada por editores estrangeiros. Por outro lado, as respostas de pesquisadores do MAST foram diametralmente opostas, ou seja, sua produção científica é publicada por editores brasileiros (figura 10). 


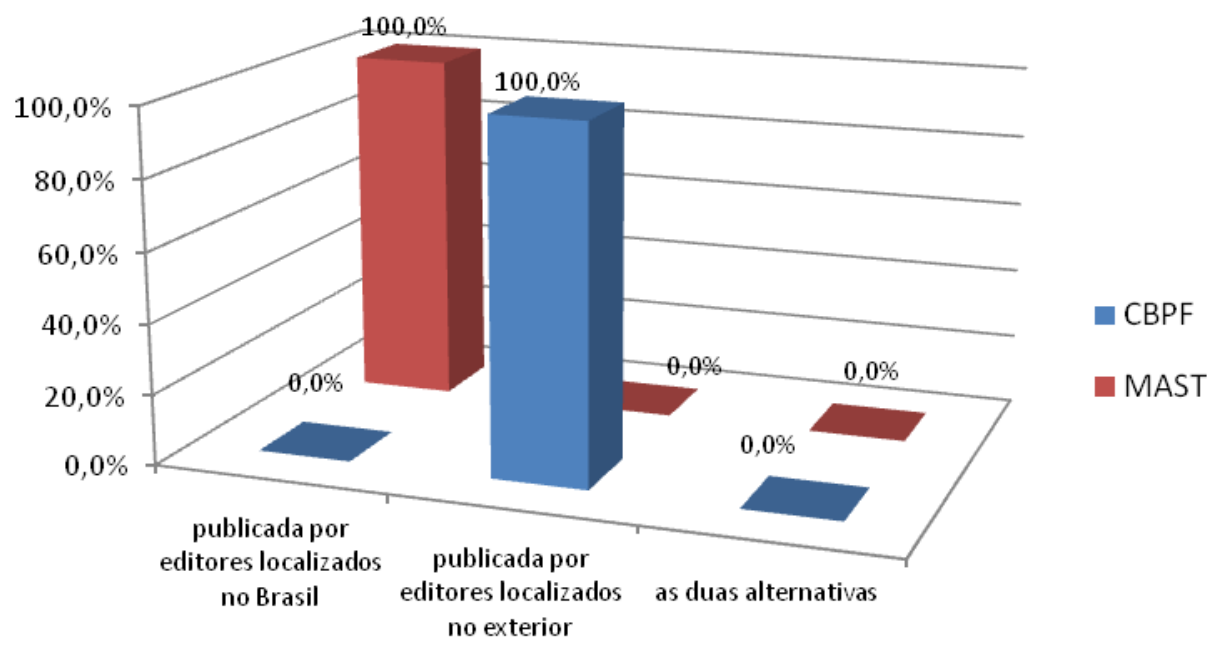

Figura 10: Origem dos editores da produção científica dos pesquisadores

Essa questão é relevante em razão do fato de que os editores são responsáveis por parte importante do fluxo da informação científica, atuando diretamente na distribuição. Por esta razão, a inserção dos resultados de pesquisa publicados em vias alternativas de comunicação depende, em grande parte, de decisões acordadas com editores, tema explorado a seguir.

Confrontados com uma situação hipotética, de os editores de suas publicações permitirem torná-las acessíveis livremente na internet, os pesquisadores foram questionados a respeito dos ambientes mais apropriados para tal. Dentre os respondentes, $64 \%$ e $50 \%$ dos pesquisadores do CBBF e do MAST, respectivamente, considerou a página da instituição, 47\% e 83\% considerou o repositório digital da instituição e $41 \%$ e $83 \%$ o repositório digital temático como os ambientes mais adequados (figura 11). Na verdade, a despeito da possibilidade de escolha da opção "não achar necessário", marcada por um pesquisador, o aspecto sobressalente das respostas a este questionamento está na indicação da necessidade de tornar a produção científica acessível em outros ambientes, além daqueles mantidos por seus editores.

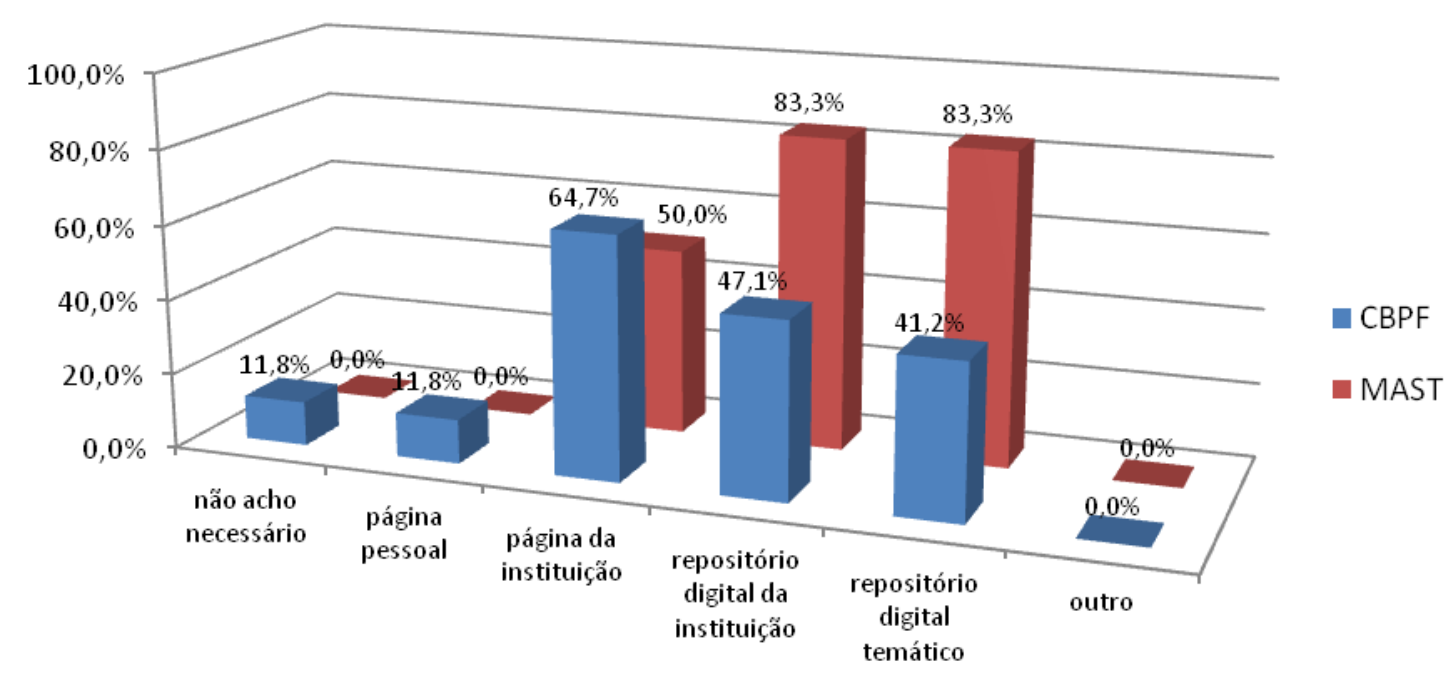

Figura 11: Ambientes mais apropriados para armazenamento e disponibilização gratuita da produção científica 
A pesquisa realizada por Over et al (2005) também atentou para essa mesma questão. Os autores questionaram os pesquisadores alemães, de todas as áreas do conhecimento, quais seriam os locais mais apropriados para tornar disponível seus e-prints. Os resultados foram bastante similares aos da pesquisa aqui relatada. Os autores descobriram que $80 \%$ dos cientistas sociais e humanistas e $82 \%$ dos cientistas consideraram que o local mais apropriado seria um repositório temático/disciplinar disponível na Internet. Seguidamente a esta opção, aquelas mais relevantes foram nas páginas pessoais dos autores, diferentemente dos resultados ora relatados.

Outro aspecto útil à compreensão dos processos de comunicação científica está relacionado aos modos como pesquisadores lidam com os direitos de cópia das publicações de sua autoria. Como já ressaltado, os modelos de licenciamento praticados por editores científicos incidem diretamente sobre maior ou menor exposição dos conteúdos junto à comunidade científica. Portanto, a negociação ou não dos direitos de cópia implicam na inserção ou não dos resultados de pesquisa em vias alternativas de comunicação, como repositórios institucionais. Esse assunto foi tratado em dois momentos no questionário. Primeiramente, os pesquisadores responderam à pergunta de como encaram os termos sobre direitos de cópia nos contratos de publicação (figura 12). Nenhum pesquisador afirmou negociar os termos relacionados com direitos autorais quando da assinatura dos contratos de publicação. Embora examinem os contratos, pesquisadores de ambas as instituições afirmaram assiná-los da forma como são elaborados pelos editores.

Entre as respostas que especificaram a alternativa 'outro', apontadas apenas por pesquisadores do MAST, foi mencionado que geralmente não assinam contratos de publicação e não há preocupação com esta questão. A outra resposta enfatizou que quando assina, entretanto, os direitos não são pagos corretamente pelas editoras, esta última, referindo-se, possivelmente, à publicação de livros.

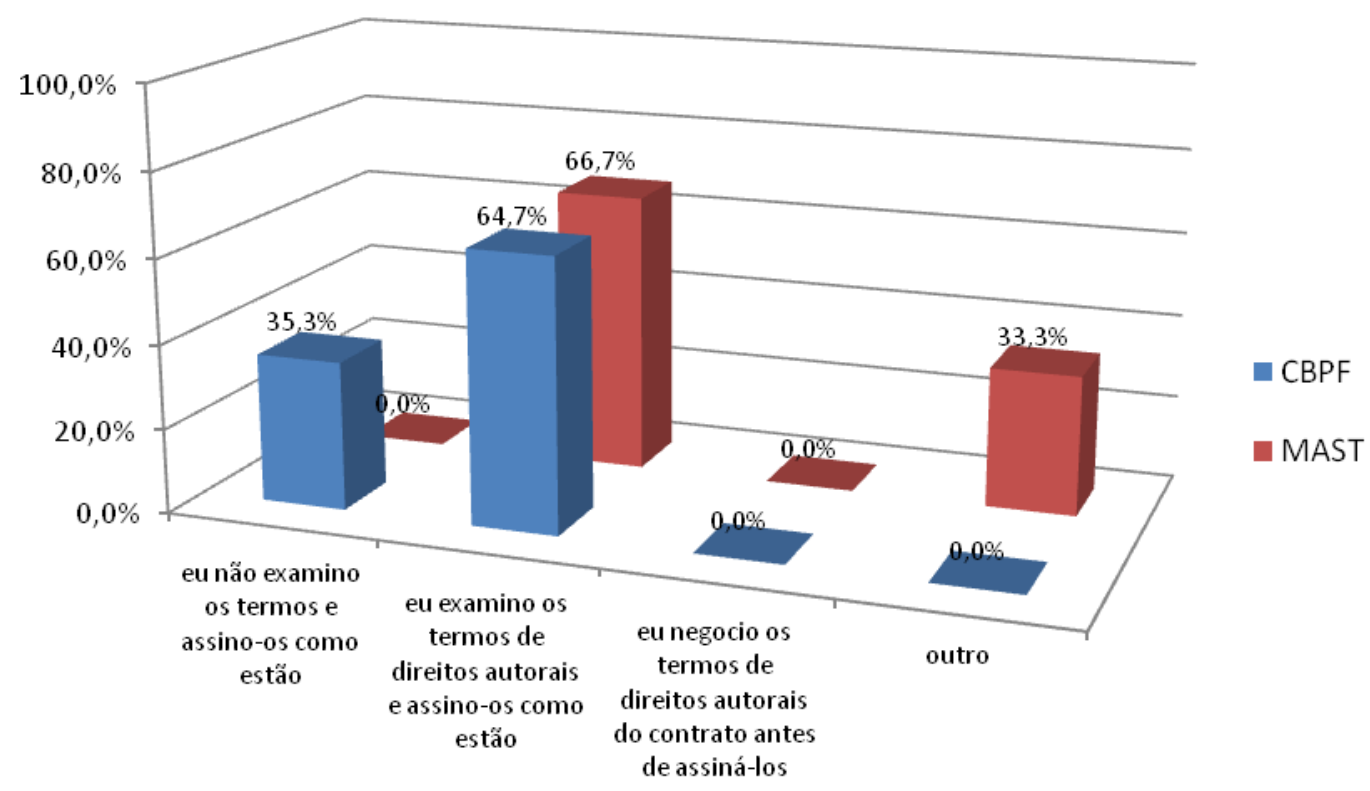

Figura 12: Reação quanto aos termos sobre direitos de cópia

Em recente levantamento, Gale (2011) explorou a posição de pesquisadores de diferentes áreas do conhecimento quando estão diante dos termos de direitos de cópia de suas publicações. Tal como os resultados aqui discutidos, Gale indica que a maior parte dos pesquisados, de todas as áreas do conhecimento, lêem e aceitam os termos, assinando-os exatamente como proposto por seus editores. A ausência de repostas que afirmam negociar os direitos de cópia significa, evidentemente, que pesquisadores não empreendem qualquer esforço de ajuste dos contratos. Gale buscou a razão disso em seu estudo, e chegou à conclusão de que a maioria não o faz por nunca ter pensado a respeito. 
O posicionamento dos pesquisadores do CBPF e do MAST é similar e sugere uma não preocupação, ou mesmo desconhecimento, com as implicações de suas decisões sobre direitos de cópia em relação à disseminação dos resultados de suas pesquisas.

No segundo momento em que essa questão foi abordada, foram exploradas as situações mais freqüentes, isto é, aquelas em que os pesquisadores se encontram frente aos direitos de cópia de suas publicações, seja em periódico científico, anais de conferências, livros ou capítulos de livros (figura 13). Ou seja, solicitou-se aos pesquisadores que assinalassem quais são as decorrências mais comuns quando concordam com os termos relacionados com direitos de cópia em seus contratos de publicação.

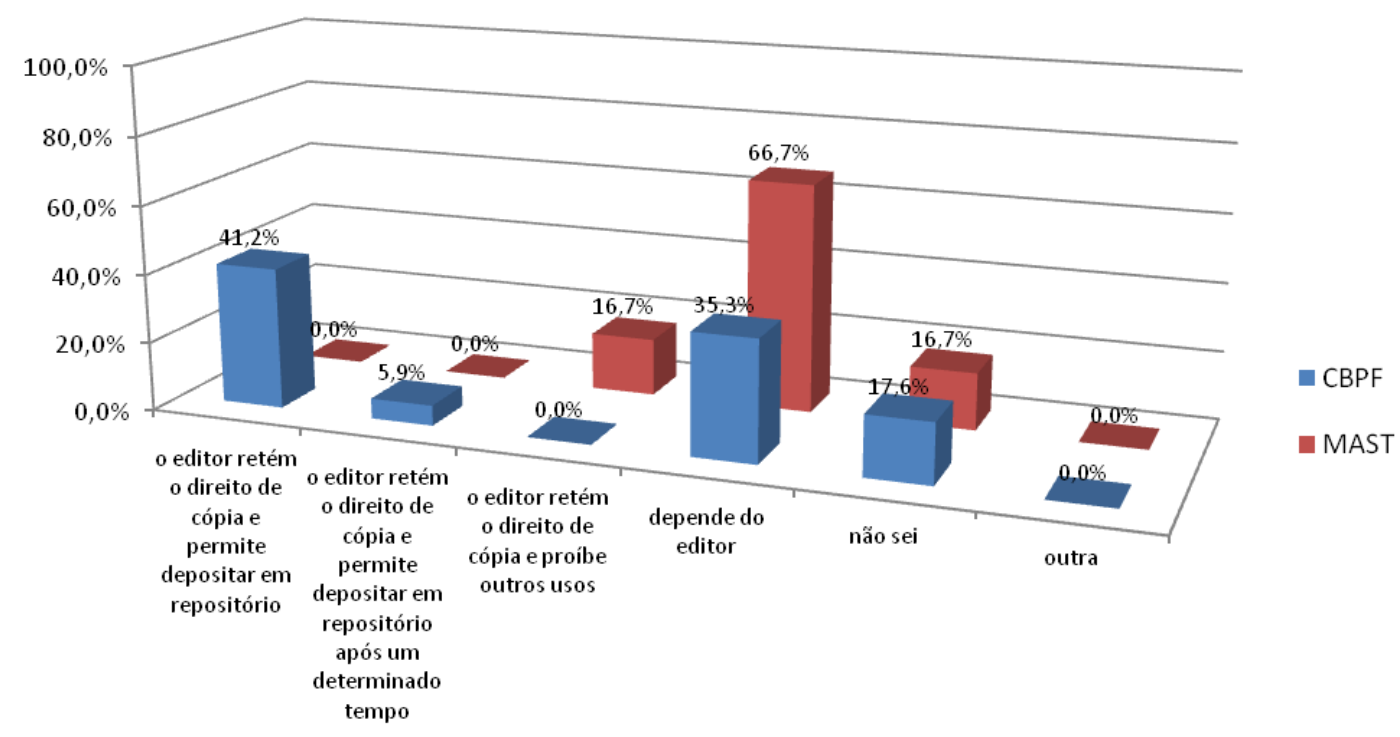

Figura 13: Situações mais frequentes em que autores se encontram frente aos direitos de cópia de suas publicações

Pesquisadores do CBPF indicaram que a situação mais frequente em que se encontram é a retenção dos direitos de cópia pelo editor e o depósito de uma cópia digital em repositório digital. Essa situação condiz que as práticas disseminadas de autoarquivamento em arquivos de e-prints, como amplamente mencionado ao longo das entrevistas. Por outro lado, pesquisadores do MAST afirmaram que tais situações dependem do editor, opção que também obteve uma quantidade considerável de repostas provenientes de pesquisadores do CBPF. De acordo com as respostas, parecem ser pouco frequentes as situações em que editores não permitem qualquer licença para distribuição eletrônica de versões dos trabalhos.

Swan (2008) estudou essa questão e chegou à conclusão de que há uma atitude fortemente positiva em relação à retenção dos direitos de cópia dos trabalhos por parte dos pesquisadores, muito embora, ressalta, poucos autores compreendam o que é necessário fazer para de fato alcançar isso. Segundo a autora, a consequência da retenção dos direitos de cópia é que os autores estarão livres para decidir sobre as permissões que regerão a reutilização dos seus trabalhos. Assim, de acordo com as expectativas expressas nas principais motivações por trás das atividades de disseminação, a maioria deles, em muitos casos, diz que deseja que seu trabalho seja utilizado livremente o tanto quanto seja possível, uma vez que há recompensas em suas carreiras decorrentes disso (SWAN, 2008).

Ainda na perspectiva da caracterização dos hábitos de comunicação científica, cientistas, cientistas sociais e humanistas puderam opinar acerca de sua visão do sistema de comunicação científica em suas áreas. Para tanto, a questão em tela considerou que a visão do pesquisador sobre o sistema de comunicação científica, de um ponto de vista geral, poderia ser expressa a partir da constatação ou não de necessidades. Perguntados como caracterizam os sistema de comunicação científica tendo por base as práticas correntes em suas respectivas áreas, pesquisadores vinculados às duas instituições mantiveram-se em posições similares (figura 14). Para a 58\% de pesquisadores do CBPF e 66\% do MAST, algumas mudanças precisam ser feitas. 


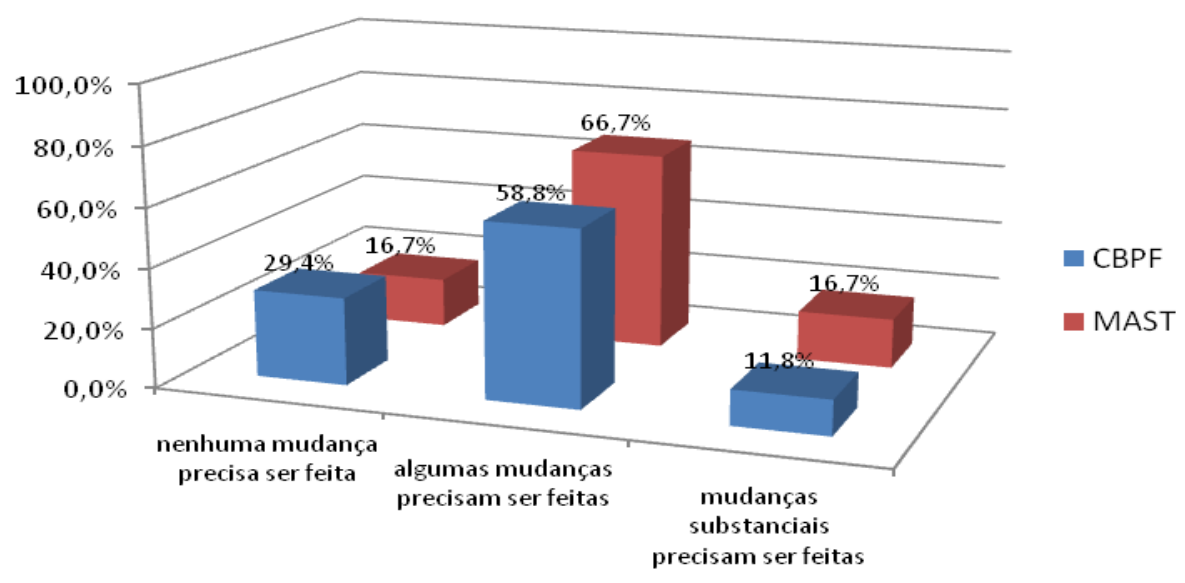

Figura 14: Visão acerca do sistema de comunicação científica

Em espaço apropriado para comentar a questão, pesquisadores do CBPF aprofundaram suas respostas. O primeiro deles ressaltou que o Brasil precisa implantar uma imprensa científica forte em todas as áreas do conhecimento, e ponderou que isso não significa depositar os artigos em um portal de livre acesso, mas, também, não implica no contrário. Para o pesquisador, o livre acesso tem custos e se realizado sem cuidado pode resultar no roubo de ideias e patentes. Cabe ressaltar que essa posição reflete o desconhecimento acerca do acesso aberto à informação científica, cujos esforços estão direcionados para aqueles conteúdos publicados ou aceitos para publicação. O segundo pesquisador que comentou a questão afirmou ser necessário acesso aberto para toda a ciência. Do mesmo modo, em outras palavras, um pesquisador do MAST afirmou que é necessário possibilitar o acesso irrestrito às versões digitais dos artigos científicos. Levando em consideração perspectivas das áreas estudadas na presente pesquisa acerca do modo como ocorre a busca, acesso, uso e comunicação da informação, a indicação de necessidade de algumas mudanças coincide com problemas apontados a partir dos dados do questionário e das entrevistas. Ou seja, muito embora a situação não seja percebida como caótica, os pesquisadores consideram sim que mudanças necessitam ser feitas, e estas estão relacionadas com as percepções expressas ao longo dos temas discutidos anteriormente.

Por último, ao serem apresentados a um conjunto de assertivas relacionadas com o sistema de comunicação científica em suas áreas, os respondentes tiveram que assinalar com quais delas concordavam (figura 15). Na perspectiva daqueles vinculados ao MAST, sobressaiu a opinião de que novas estratégias de disseminação de resultados de pesquisa terão importância aumentada em sua área nos próximos anos, considerando, possivelmente, os avanços tecnológicos. Seguidamente, com ocorrência de mais da metade dos pesquisadores, aquela que afirmou que o sistema de comunicação científica não atende às necessidades dos pesquisadores. Esta última perspectiva recebeu a segunda menor atenção por parte dos físicos. De acordo com as alternativas escolhidas, embora de forma não concentrada, os físicos consideraram que o sistema de comunicação da forma como está funcionando atende às diferentes dimensões do fazer científico (produção colaborativa, pesquisa interdisciplinar e interação entre áreas e necessidades dos pesquisadores). A despeito das inúmeras ressalvas feitas ao longo do estudo, é possível que o contentamento expresso por físicos seja explicado pelo fato de que as novas oportunidades decorrentes dos inúmeros avanços em termos de gestão e comunicação da informação científica não beneficiam igualmente a todos os pesquisadores. 


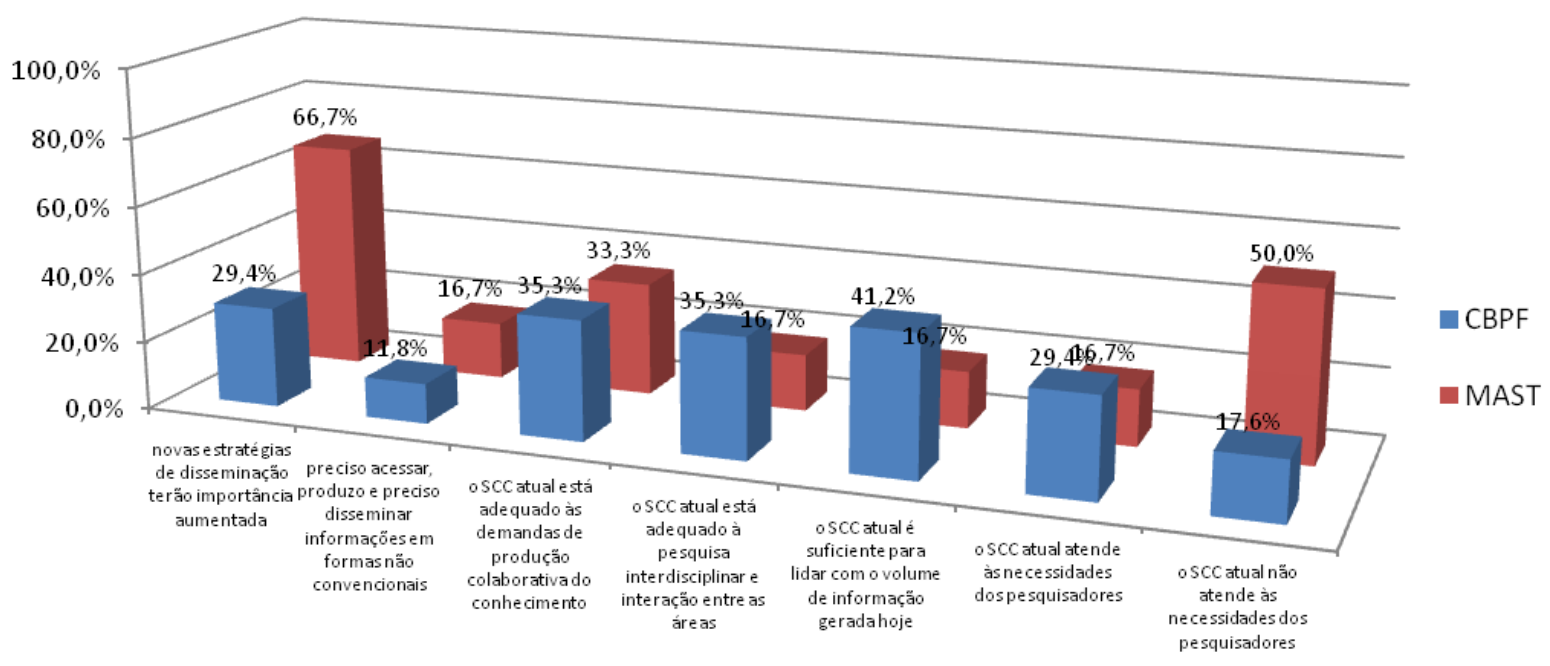

Figura 15: Possíveis mudanças no sistema de comunicação científica

\section{Considerações finais}

Resultados obtidos na presente pesquisa permitiram concluir que as atividades de busca, acesso e uso da informação científica nos dias atuais são fortemente influenciadas pelas tecnologias de informação e comunicação. Os resultados permitiram ainda identificar como as práticas de busca, acesso e uso se realizam além de propiciar conhecimento sobre hábitos de comunicação. Os resultados do estudo permitiram concluir que:

- independentemente da área do conhecimento, há um forte envolvimento com a busca e acesso à informação científica em formato digital e disponível na internet. As tecnologias têm contribuído para o aumento do volume de informação científica disponível digitalmente e online, mudando, consequentemente, as atividades de busca, acesso e disseminação da informação por parte de pesquisadores de áreas investigadas;

- para físicos, a acessibilidade às informações que necessitam está amplamente condicionada à existência dos arquivos de e-prints, enquanto que pesquisadores das duas áreas consideram o Portal de Periódicos da CAPES;

- pesquisadores das duas áreas estudadas buscam, acessam e utilizam um conjunto de recursos de informação científica constituído de artigos de periódicos científicos, artigos publicados em anais de conferências e livros que constituem o core dos principais insumos informacionais;

- para físicos, o artigo de periódico científico, em suas diferentes versões digitais (eprints) constitui o principal insumo informacional para as atividades de pesquisa. Para cientistas sociais e humanistas o artigo de periódico assume também um importante papel, porém, dividindo espaço equilibradamente com artigos publicados em anais de conferências e livros;

- diferentemente das práticas de busca e acesso, que ocorrem prioritariamente em meio digital nas duas áreas, o uso propriamente dito ocorre ainda em suporte impresso em ambas as áreas;

- por conta da dependência da circulação precoce e desimpedida da informação científica, físicos estão completa e intuitivamente inseridos na lógica do acesso aberto à informação científica; 
- hábitos de disseminação são estimulados por motivações comuns a físicos e a cientistas sociais e humanistas;

- a principal motivação para disseminar resultados de suas pesquisas é tornar público o conhecimento gerado de modo que outros possam utilizá-los e gerar novos conhecimentos, seguida de necessidade de visibilidade e validação, além avaliação institucional também constituem fortes motivações;

- a escolha do veículo de publicação está intimamente relacionadas com as motivações para publicar e condicionada pela reputação do periódico ou da editora. Fator de impacto, existência de versão digital, disponibilidade na Internet e a disseminação em nível internacional constituem fatores relevantes para as duas áreas;

- tal como ocorre com a busca e o acesso, físicos publicam os resultados de suas pesquisa preponderantemente em artigos de periódicos científicos; do mesmo modo cientistas sociais e humanistas o fazem equilibradamente em artigos de periódicos científicos, artigos de anais de conferências, capítulos de livros (edições organizadas) e, em menor quantidade, livros.

\section{Referências}

BARUCHSON-ARBIB, S.; BRONSTEIN, J. Humanists as information users in the digital age: the case of jewish studies scholars in Israel. Journal of the American Society for Information Science and Technology, v. 58, n. 14, 2007, p. 22692279.

BORGMAN, C. L. Scholarship in the digital age: information, infrastructure, and the internet. Cambridge, Londres: MIT Press, 2007. 336p.

BROCKMAN, W. S. et al. Scholarly work in the humanities and the evolving information environment. Washington, DC: Council on Library and Information Resources, 2001.38p.

BROWN, C. M. Information seeking behavior of scientists in the electronic information age: astronomers, chemists, mathematicians, and physicists. Journal Of The American Society for Information Science and Technology, v. 50, n. 10, 1999.

BROWN, C. M. The coming of age of e-prints in the literature of physics. Issues in Science and Technology Librarianship, 2001.

BUDD, J.; CHRISTENSEN, C. Social sciences literature and electronic information. Libraries and the Academy, v. 3, n. 4 2003, p. 643-651

COCKERILL, M. Business models in open access publishing. In: JACOBS, N. (Ed.). Open access: key strategic, technical and economic aspects. Chandos Publishing: Oxford, 2006.

E-Resources for Research in the Humanities and Social Sciences, 2005.

GENTIL-BECCOT, A. et al. Information resources in high-energy physics: surveying the present landscape and charting the future course. 2008.

GORRAIZ, J. et al. International publication output and research impact in social sciences: comparison of the Universities of Vienna, Zurich and Oslo. Research Evaluation, v. 18, n. 3, 2009, p. 221-232.

GUMIEIRO, K. A. Modelos de negócios para periódicos científicos eletrônicos de acesso aberto. 2009. 157 f. Dissertação (Mestrado em Ciência da Informação). Universidade de Brasília, Brasília, 2009.

HARIDASAN, S.; KHAN, M. Impact and use of e-resources by social scientists in National Social Science Documentation Centre (NASSDOC), India. The Electronic Library, v. 27, n. 1, 2009, p. 117-133.

HEMMINGER, B. M. et al. Information seeking behavior of academic scientists. Journal Of The American Society for Information Science and Technology, v. 58, n. 14, 2007. 
HUANG, M.; CHANG, Y. Characteristics of research output in social sciences and humanities: from a research evaluation perspective. Journal of the American Society for Information Science and Technology, v. 59, n. 11, 2008, p. 1819-1828

HURD, J. M. Models of scientific communication systems. In: CRAWFORD, S. Y.; HURD, H. M.; WELLER, A. C. From print to electronic: the transformation of scientific information. Medford: Asis, 1996. p.9-33.

HURD, J. M. Scientific communication: new roles and new players. Science \& Technology Libraries, v. 25, n. 1, 2004, p. 5-22

HURD, J. M. The transformation of scientific communication: a model for 2020. Journal of the American Society for Information Science, v. 51, n. 14, 2000, p.1279-1283.

JAMALI, H. R.; NICHOLAS, D. Information-seeking behavior of physicists and astronomers. Aslib Proceedings: New Information Perspectives, v. 60, n. 5, 2008, p. 444-462.

KAPLAN, N.; STORER, N. W. Scientific communication. In: SILLS, D. L. International encyclopedia of the social sciences. New York: Macmillan, v.14, p.112-117, 1968.

LANCASTER, F. W.; SMITH, L. C. Science, scholarship and the communication of knowledge. Library Trends, v. 27, n. 3, p. 367-387, 1978

LAWAL, I. Scholarly communication: the use and non-use of e-print archives for the dissemination of scientific information. Issues in Science and Technology Librarianship, 2002.

MARON, N. L.; SMITH, K. K. Current models of digital scholarly communication. Washington, DC: Association of Research Libraries, 2008. $49 \mathrm{p}$

MENZEL, H. Scientific communication: five themes from social science research. American Psychologist, v.21, n.10, p.9991004,1966

MIKHAILOV, A. I, et al. Scientific communications and informatics. Arlington: Information Resources, 1984.402 p.

MOORE, G. Survey of University of Toronto faculty awareness, attitudes, and practices regarding scholarly communication: a preliminary report. Toronto: University of Toronto, 2011. 185p.

ODLYZKO, A. Economic costs of toll access. In: JACOBS, N. (Ed.). Open access: key strategic, technical and economic aspects. Chandos Publishing: Oxford, 2006.

OVER, A. et al. Publishing strategies in transformation? Weinheim: Wiley-VCH Verla, 2005. 65p.

PINFIELD, S. How do physicists use an e-print archive? Implications for institutional e-print services. D-Lib Magazine, v. 7, $\mathrm{n}$. $12,2001$.

ROOSENDAAL, H.E.; GEURTS, P.A.T.M. Forces and functions in scientific communication: An analysis of their interplay. 1998

ROWLANDS, I.; NICHOLAS, D. Scholarly communication in the digital environment: the 2005 survey of journal author behaviour and attitudes. Aslib Proceedings: New Information Perspectives, v. 57, n. 6, 2005, p. $481-497$.

SøNDERGAARD, T. F. et al. Documents and the communication of scientific and scholarly information: revising and updating the UNISIST model. Journal of Documentation, v. 59, n. 3, p. 278-320, 2003

SPARKS, S. JISC disciplinary differences report. London: Lincoln House, 2005. 92p.

SUBER, P. Open access overview: focusing on open access to peer-reviewed research articles and their preprints. 2010.

SWAN, A. Journal authors survey: report. Cornwall: Key Perspectives, 2004. 77p.

SWAN, A. Key concerns within the scholarly communication process: report to the JISC Scholarly Communications Group. Truro: Key Perspectives Ltd, 2008. 65p.

SWAN, A. The culture of open access: researchers' views and responses. In: JACOBS, N. (Ed.) Open access: Key strategic, technical and economic aspects. Oxford: Chandos, 2006.

SWAN, A.; BROWN, S. Authors and open access publishing. Learned Publishing, v. 17, 2004, p. $219-224$.

SWAN, A.; BROWN, S. Open access self-archiving: an author study. Cornwall: Key Perspectives, 2005. 97p.

UNISIST. Study report on the feasibility of a world science information system. Paris: UNESCO, 1971. 161p.

VASKA, M. Introducing grey literature. In: PEJŠOVÁ, P. Grey literature repositories. Slim: Verbal, 2010. p. 11-19. 
WILLINSKY, J. The access principle: the case for open access to research and scholarship. Massachusetts: MIT Press, 2006. 287p.

YANG, S. et al. An empirical study on the utilization of web academic resources in humanities and social sciences based on web citations. Scientometrics, v. 84, 2010, p. 1-19.

\section{Dados do autor}

\section{Fernando César Lima Leite}

Graduado em Biblioteconomia. Mestre em Ciência da Informação. Doutor em Ciência da Informação. Experiência na área de Ciência da Informação, atuando principalmente nos seguintes tópicos: informação em ciência e tecnologia, gestão da informação e do conhecimento científico, biblioteconomia, planejamento e implementação de serviços de informação em C\&T em ambiente digital, comunicação científica, divulgação científica, acesso aberto e repositórios institucionais, periódicos científicos eletrônicos. Editor pelo Brasil do ELIS Eprints in Library and Information Science (repositório temático internacional da produção científica em Ciência da Informação). Foi analista da Empresa Brasileira de Pesquisa Agropecuária (Embrapa) onde planejou e implementou atividades de gestão da informação científica, tecnológica e organizacional e coordenou iniciativa e estratégias de acesso aberto à informação científica. Consultor do IBICT entre 2006 e 2009. Especialista Visitante do IBICT entre 2010 e 2013, no âmbito do Programa de Capacitação Institucional (PCI/CNPQ). É professor adjunto da Faculdade de Ciência da Informação da Universidade de Brasília.

fernandodfc@gmail.com

Recebido - Received : 2014-10-23

Aceitado - Accepted : 2014-12-30

\footnotetext{
${ }^{1}$ Das 74 solicitações, 23 foram respondidas, o que corresponde a 32\% dos pesquisadores, sendo 17 respondentes do CBPF e seis do MAST. 2 Do CBPF foram entrevistados quatro pesquisadores e do MAST foram entrevistados três pesquisadores.

3 A lista de verificação foi aplicada nos currículos Lattes e Diretório de Grupos de Pesquisa de todos pesquisadores doutores das dois institutos de pesquisa selecionados para o estudo (56 pesquisadores do CBPF, pois dois não possuíam cucrrículo Lattes, e 16 pesquisadores do MAST).
}

\section{(cc) $\mathrm{BY}$}

This work is licensed under a Creative Commons Attribution 4.0 United States License.

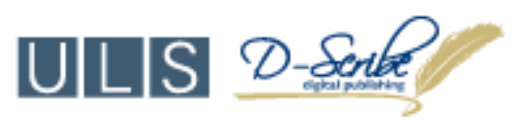

This journal is published by the University Library System of the University of Pittsburgh as part of its D-Scribe Digital Publishing Program and is cosponsored by the University of Pittsburgh Press. 